Article

\title{
Intraday Market-Wide Ups/Downs and Returns
}

\author{
Wei Zhang ${ }^{1,2}$, Shen Lin ${ }^{1,2}$ and Yongjie Zhang ${ }^{1,2, *}$ \\ 1 The College of Management and Economics, Tianjin University, Tianjin 300072, China; weiz@tju.edu.cn; \\ linshen@tju.edu.cn \\ 2 China Center for Social Computing and Analytics, Tianjin University, Tianjin 300072, China \\ * Correspondence: yjz@tju.edu.cn
}

Received: 12 August 2016; Accepted: 21 September 2016; Published: 11 October 2016

\begin{abstract}
Using stock market data over 16 years for Chinese stock markets and over 3 years for U.S. stock markets, this study explores the explanatory power of early intraday market-wide up and down movements to the subsequent intraday returns within the same trading day. As compared to the closing of the previous trading day, we introduce two intraday market-wide up/down indicators in terms of the index return and the proportional difference in the numbers of stocks moving upwards to downwards at each minute. A time series analysis shows an economically and statistically significant positive relation between the intraday indicators and the subsequent intraday returns of the market indices. Intraday trading strategies that exploit this intraday relationship lead to monthly returns of $4.1 \%$ in the Chinese market and $2.8 \%$ in the U.S. market. In addition, the strategies are more profitable in markets with high activity of individual investors (i.e., high trading value, low trading volume per transaction, small-cap, high B/M ratio, low institutional ownership, low price, and high number of shareholders). The results indicate that simple intraday market-wide up/down movements in the earlier trading affect the sentiment of retail investors, resulting in market movements in the same direction within the trading day.
\end{abstract}

Keywords: Intraday market-wide movements; Intraday returns; Investor sentiment; Individual (retail) investors

\section{Introduction}

Among various financial market indicators, the up and down movements of market index levels and stock prices relative to the previous day are probably the simplest and most important indicators for investors. However, it is not clear whether these market-wide ups and downs in the earlier trading periods actually contain information about the subsequent intraday returns. Casual observations from the Chinese stock market show that a market-wide up/down trend in the earlier trading day at, say, 10:30 am, can predict the subsequent intraday return from 10:30 am to the end of the trading day. In this study, we consider two signal 
indicators (predictors) at any point of the trading day. The first is the Index Signal, defined by the index return at the time relative to the closing index level of the previous trading day. It captures the overall up and down market movement at any point of the trading day with respect to the previous day. The second is the Up-Down Signal, defined by the proportional difference in the total number of up stocks to the number of down stocks at any point in the trading day as compared to their closing prices on the previous day. It measures the overall stock movement (with respect to the percentage of stocks moving up to the percentage of stocks moving down) at any point of the trading day. Using 16 years of data from the Chinese stock market and 3 years of data from the U.S. stock market at each minute of the trading day, we investigate whether these intraday signal indicators can predict the subsequent intraday market returns. We find that, in the most minutes of trading days, both indicators significantly explain the subsequent intraday return from the minute to the end of the trading day. That is, knowing that a positive early intraday return in the index or that there are more stocks moving upwards than downwards at 10:30 am (relative to the previous day) has explanatory power for the index intraday return from 10:30 am to the end of the trading day. This effect is statistically significant in the Chinese and U.S. markets. While there is extensive evidence of intraday patterns in volume and volatility (see, for example, Wood, McInish, and Ord (1985), Harris (1986), Jain and Joh (1988)), this is the first study to our knowledge that provides evidence that the up and down movements of market indices and stocks can predict the subsequent intraday returns of the market. More importantly, the intraday trading strategies that exploit this intraday prediction can generate significant excess returns. A cross-sectional analysis shows that applying the Up-Down Signal on the stocks with high activity of retail investors, the intraday strategy can generate a monthly return of $4.1 \%$ in the Chinese market and $2.8 \%$ in the U.S. market.

We consider several potential explanations of the predictive power of the intraday returns. First, our main concern is that the intraday predictability may be due to trading constraints in the Chinese markets, such as the " $\mathrm{T}+1$ " rule and no-short-selling. As an emerging market, these constraints are important attributes of the Chinese stock market. For instance, the strategy return could be created by the impossibility of short-sale arbitrage if the return is primarily a result of short-only trading. By grouping the strategy returns to long-only and short-only, we find no evidence that the strategy returns in the Chinese market are due to the short-sale constraint. More interestingly, we find that the returns for the long-only strategies are much higher than that for the long-and-short strategies, which suggests that the profits of the intraday strategies become more significant under the short-sale constraint. In addition, without short-sale constraints, we obtain similar results in the U.S. market. All these results provide no evidence that the explanatory power of the intraday indicators is due to trading constraints.

Second, systemic risk could be another potential source of the intraday strategy returns. Due to asymmetrical long-short trading times, systemic risk can provide payoffs in the form of strategy return. To examine this potential source, we include three systemic risk factors (Fama and French $(1992,1993,1996)$ ) into our analysis. We find no evidence that the strategy return is generated by taking systemic risk and adopting the beta strategy. Furthermore, all the volatility measures significantly and positively explain the strategy returns.

Finally, we examine whether the strategy returns can be explained by the activity of individual investors and the intraday sentiment. Following Kumar and Lee (2006), we use some group standards (such as the total trading value, trading value per transaction, and turnover rate), firm characteristics (including market capitalization, book to market ratio, stock price, shareholding ratio of 10 primary shareholders), and the 
number of shareholders to identify popular stocks for retail investors and to construct portfolios. We then conduct a cross-sectional analysis to examine if the intraday strategy applied to the more popular stocks among retail investors can generate higher strategy returns. The results provide strong evidence that high retail investor activities explain the high return of the intraday strategy.

If we interpret the high activities of retail investors as investor sentiment, the above results indicate that the intraday strategy returns are more likely driven by the intraday sentiments of retail investors. When the market is dominated by naïve individual investors, they are more likely to be affected by the most recent performance of the market index and the overall up and down movement of the stock prices. Due to this shortterm sentiment, investors are more likely to move the market in the same direction over the rest of the trading day. Intuitively, the two intraday signals or predictors could be interpreted as two market intraday sentiment sources. At most times on the trading day, both predictors have a significantly positive impact on the intraday market returns, though the Up-Down Signal performs better than the Index Signal. Furthermore, the Up-Down Signal-based strategy in the morning of the trading day can generate an average daily return of 14 bias points (BPs) in the Chinese market in the 16 years' worth of data examined.

To illustrate this intraday investor sentiment, we consider as an example an extreme event in the Chinese stock market at the beginning of 2016. The Chinese stock market experienced a huge bubble and crash caused by retail investor leverage between 2014 and 2016. The major market index, Shanghai Stock Exchange (SSE) Composite Index (SSECI), started from about 2,000 in June 2014 and increased until it reached 5,178 on June 12 , 2015. Thereafter, a sudden market falling led to a series of forced sales due to high leveraged long positions held by individual investors, which made the stock price fall off a cliff in the next two months. The SSECI stayed at around 3,500 until the end of 2015. To prevent the dramatic fall from occurring again, the SSE introduced the circuit breaker (CB) in the Chinese market on January 1,2016, which is an important policy in the U.S. stock market. The CB in the Chinese market is a two-step breaker. When the major index falls by over $5 \%$, trading is halted in the market for 15 minutes. Furthermore, if the major index falls by over $7 \%$, all trading is suspended for the rest of the day. The CB is meant to calm the market down by slowing the overreaction of investors to trading activities that are unrelated to fundamentals. However, on January 4, 2016, the first time that the CB was implemented, the trading time between the two-step CB only took 6 minutes. The second CB took place early in the morning on January 7, 2016, and the two-step CB time was further reduced to 3 minutes. During the week, the SSECI fell by $9.97 \%$ and the CB policy only survived for one week before being revoked by the SSE on January 8, 2016. Clearly, the fundamental value of the stock market could not vary so much over such short time periods. A primary explanation, which has also been confirmed by the SSE, is that the first CB with a threshold value of $5 \%$ caused a systemic panic among retail investors who form the majority of the participants of the Chinese stock markets. Hence, the trading prohibition ferments retail investors' sentiment, which leads to the second CB in a very short time period.

Additionally, this intraday pattern is also found in the U.S. stock markets. All the results based on the regression analysis of sentiment signals on the intraday return and strategy return and cross-section analysis of strategy returns are consistent with the ones in the Chinese market, though the strategy returns are smaller but statistically significant. This suggests that variation in intraday sentiment occurs even in the more mature U.S. market with many arbitrageurs and less trade limitations.

This study is closely related to return predictability in the literature. In rational models, with rational investors and arbitrageurs, the sentiment of individual investors should not affect stock price. However, 
Shleifer and Summers (1990) propose several approaches showing that the sentiment and social interaction of noise traders can systemically affect stock prices. In several behavioral finance models, past returns are regarded as a source of sentiment that can affect investors' expectation (Barberis, Greenwood, Jin, and Shleifer (2015), Barberis, Shleifer, and Vishny (1998)).

This study is also closely related to the study of intraday price patterns. In the existing literature, most intraday studies focus on microstructure issues such as pricing efficiency and mechanism design. Heston, Korajczyk, and Sadka (2010) examine the intraday return and find return continuation at 30-minutes intervals. Other trading data, including data on volume and volatility, have also been used in these studies, but they cannot explain the return patterns that last for 40 trading days. More recently, Gao, Han, Li, and Zhou (2015) argue that the return in the first half-hour can predict the return in the last half-hour. However, the existing intraday studies provide a limited explanation of the intraday return pattern.

Moreover, this study is also related to the literature on investor sentiment extraction. After the introduction of sentiment in financial markets (Shleifer and Summers (1990)), empirical studies focus on finding an adequate proxy to measure the overall market sentiment. In financial markets, the closed-end fund premium is the earliest sentiment-related anomaly (Lee, Shleifer, and Thaler (1991)). Chen, Kan, and Miller (1993) and Chopra, Lee, Shleifer, and Thaler (1993) show the feasibility of measuring the market sentiment with the premium level, while Stigler (1964) and Ritter (1991) use first-day returns of the initial public offering (IPO) market. Additionally, the share of equity issues in total equity and debt issues, which represents investor enthusiasm, can also be used. Among many other measures in the literature, the most influential is the one designed by Baker and Wurgler (2006), who use principal component analysis to extract the common component in six wellaccepted sentiment proxies. The Baker and Wurgler index successfully captures the underlying sentiment alterations in the stock market and has been used widely (Stambaugh, Yu, and Yuan (2012, 2014); Huang, Jiang, Tu, and Zhou (2014); Antoniou, Doukas, and Subrahmanyam (2013); Yu (2013)).

The other way to measure investor sentiment is by using the "big data" approach. Among the representative work, Antweiler and Frank (2004) extract the sentiment of 1.5 million messages from the stocklinked internet message board, Yahoo! Finance and Raging Bull, and study the relationship between the bullishness of these messages and the corresponding stock performance. There are a number of follow-up sentiment measures but none of these measures are economically significant predictors of future stock returns (Das and Chen (2007); Zhang, Fuehres, and Gloor (2012); Bollen, Mao, and Zeng (2011)). Textual analysis has also been used in financial news (Tetlock $(2007,2008,2011)$ ) and official company reports (Jegadeesh and Wu (2013); Loughran and McDonald (2009)). The most interesting and sentiment related study is Tetlock (2007), who tests the interactions between the market-width media and stock market return using daily contents from the popular Wall Street Journal column called "Abreast of the Market", which reports news regarding yesterday's market conditions and other related issues. Due to the limited number of authors of this column, the sentiment of articles cannot be deemed as a measure of market sentiment. However, Tetlock (2007) finds that high media pessimism predicts downward pressure on market prices followed by a reversion to fundamentals. This implies that the article sentiment is spread to many investors who can move the stock price over short time periods. We can treat the sentiment signals built in this study as the media, which are however more powerful due their construction using intraday market data.

This paper is structured as follows. In Section 2, we describe the data, introduce two market-wide updown signal indicators, and then present the main findings regarding the predictive ability of the intraday 
sentiment signal on the subsequent intraday returns. In Section 3, we examine several possible explanations of the intraday return pattern. In Section 4, we study the performance of the intraday strategy in the U.S. market. We conclude in Section 5.

\section{Data Description and Main Result}

In this section, we provide a description of the intraday data of the Chinese stock markets. To explore the impact of the intraday market fluctuations on the previous day on the subsequent intraday market returns, we introduce two market-wide intraday up and down movement signals or predictors, Index Signal and UpDown Signal. First, we investigate the explanatory power of the market-wide up and down signals and demonstrate an economically and statistically significant positive relation between the intraday indicators and the subsequent intraday market returns. Second, to exploit the prediction power of the intraday signals, we construct trading strategies based on the positive relationship and examine their performance.

\subsection{Data}

Our data sample includes the intraday index level and stock prices at every minute of all the firms listed in the Shanghai Stock Exchange (SHSE) and Shenzhen Stock Exchange (SZSE) from January 1, 2000, to August 31,2015 , providing data for 3,769 trading days of 2,877 stocks from "Wind" data, which is the most widely used data in the Chinese financial industry and research. The market index data include the intraday price level at each minute and daily price level of the SHSE composite index (SHSECI) and the SZSE composite index (SZSECI), the two major indices in the Chinese stock markets. The intraday index levels or stock prices at every minute are used to calculate the intraday returns. To explore the potential explanations in the following section, we also use monthly and quarterly data in the cross-section analysis.

The intraday data at each minute include the open price (the price of the first trade for each minute), close price (the price of the last trade for each minute), trading volume, and value. Daily data include the open, close, volume, value, turnover rate, and the number of transactions for each day. With the value and number of transactions, we follow Shapira and Venezia (2001) to calculate the value per transactions (VPT), where VPT=the total value of all the transactions number of transactions, which is a key variable to measure the activity of individual investors (see the details in section 3.3.). Quarterly data about the firm characteristics include market capitalization (Size, which is the close price of the last quarter times the number of shares outstanding), book to market ratio ( $B / M$, which is the book value divided by the market capitalization of the last quarter), and the number of shareholders in the stock market.

\subsection{Measuring the Intraday Signal}

We now introduce two intraday signals or predictors to measure the intraday movements of the overall market indices and stocks.

1) The intraday index signal. The market indices, the SHSECI and SZSECI, play a very important role in the Chinese stock markets. They are the official exchange indices that are widely covered by the financial media. The intraday index returns reflect the overall market movements at the intraday level. For any given minute $m$ of a trading day $t$, the Index Signal (IS) is simply defined by the intraday index return at $m$ from the closing index level of the previous trading day $t-1$, 


$$
I S_{m}^{t}=\frac{\text { Index }}{t}=1
$$

where Index $x_{m}^{t}$ is the index level at the intraday time $m$ of day $t$ and Index end represents the closing index level of the previous trading day $t-1$. Here $m$ represents any minute from 9:30 am to 11:30 am in the morning and 1:00 pm to 3:00 pm in the afternoon of a trading day in the Chinese stock markets. Intuitively, IS is the first piece of information received when investors enter the market at time $\mathrm{m}$.

We focus on the intraday IS of the Shanghai Index, SHSECI. Although both the Shanghai and the Shenzhen indices represent different market situations, their intraday IS signals are very close to each other due to their extremely high correlation. In addition, the SHSE is designed as the main stock market exchange in China and is more widely covered by the media than the SZSE.

2) The intraday Up-Down signal of stocks. Apart from the intraday index return signal, investors also pay attention to the numbers of stocks moving upwards and downwards, though both signals can be highly correlated. This is due to the limited attention of investors to the intraday stock price movements when they entry the market. We aggregate the intraday movement of all the stocks to an Up-Down signal (UDS),

$$
U D S_{m}^{t}=\frac{\left(\text { Num }_{m, t}^{u p}-N_{u m}^{\text {down }}\right)}{\left(\text { Num }_{m, t}^{u p}+\text { Num }_{m, t}^{-}+N u m_{m, t}^{\text {down }}\right)},
$$

where $N_{u m}^{c} m_{t} c \in\{U p,-, D o w n\}$ represents the number of stocks at the intraday time $m$ in day $\mathrm{t}$ whose prices move up, down, or stay the same as compared to their closing prices on the previous day. As in $I S, m$ is any minute in the trading day. We only consider the trading stocks since the stocks in suspension period usually have unannounced events, and it is difficult to measure the direction of the event-lead impact.

We combine all the stocks in the two exchanges when calculating the UDS because there is no difference between investing in the stocks listed in the SHSE and SZSE for individual investors. In addition, the trading accounts in the two exchanges are opened simultaneously and all the stocks in each exchange can be traded by all investor, independent of the exchanges.

To illustrate the two signals defined above, we consider a simple example. At 9:45 am today, assume that the SHSECI is 2,525, rising $1 \%$ from yesterday's closing index level of 2,500. At this moment, the IS is therefore 0.01 . Meanwhile, there are 3,000 stocks trading today in the market. Among them, there are 2,000 stocks with rising prices, 200 stocks with no change in prices, and 800 stocks with falling prices as compared to their closing prices of yesterday. In this case, the UDS is 0.4 , which means that there are $40 \%$ more rising stocks than falling stocks at 9:45 am as compared to yesterday. We can calculate the market-wide up and down movement signals at every minute of all the trading days. We are interested in if these intraday signals at 9:45 am can predict the intraday return of the market index from 9:45 am to the end of the trading day across all the trading days in the sample. 
Table 1. Statistics of Intraday Signals

\begin{tabular}{|c|c|c|c|c|c|c|c|c|c|}
\hline \multicolumn{10}{|c|}{ Panel A. General Statistics } \\
\hline \multirow{2}{*}{\multicolumn{2}{|c|}{$m$}} & \multicolumn{4}{|c|}{ UpDown Signal (UDS) } & \multicolumn{4}{|c|}{ Index Signal (IS) } \\
\hline & & $9: 30 \mathrm{am}$ & $10: 30 \mathrm{am}$ & $1: 00 \mathrm{pm}$ & $2: 00 \mathrm{pm}$ & $9: 30 \mathrm{am}$ & 10:30 am & $1: 00 \mathrm{pm}$ & 2:00 pm \\
\hline Min & & -0.998 & -0.991 & -0.995 & -0.994 & -0.085 & -0.056 & -0.068 & -0.073 \\
\hline Mean & & -0.047 & 0.010 & 0.020 & 0.052 & 0.000 & 0.000 & 0.000 & 0.000 \\
\hline Median & & -0.046 & 0.018 & 0.020 & 0.046 & 0.000 & 0.000 & 0.000 & 0.000 \\
\hline Max & & 1.000 & 1.000 & 1.000 & 1.000 & 0.061 & 0.059 & 0.065 & 0.089 \\
\hline S. D. & & 0.527 & 0.519 & 0.575 & 0.590 & 0.006 & 0.007 & 0.010 & 0.012 \\
\hline \multicolumn{10}{|c|}{ Panel B. Correlation Coefficients } \\
\hline & & \multicolumn{4}{|c|}{ UpDown Signal (UDS) } & \multicolumn{4}{|c|}{ Index Signal (IS) } \\
\hline$m$ & & $9: 30 \mathrm{am}$ & $10: 30 \mathrm{am}$ & $1: 00 \mathrm{pm}$ & $2: 00 \mathrm{pm}$ & $9: 30 \mathrm{am}$ & $10: 30 \mathrm{am}$ & $1: 00 \mathrm{pm}$ & 2:00 pm \\
\hline \multirow{4}{*}{ UpDown Signal } & $9: 30 \mathrm{am}$ & 1.000 & & & & & & & \\
\hline & 10:30 am & 0.541 & 1.000 & & & & & & \\
\hline & $1: 00 \mathrm{pm}$ & 0.463 & 0.765 & 1.000 & & & & & \\
\hline & 2:00 pm & 0.398 & 0.705 & 0.879 & 1.000 & & & & \\
\hline & 9:30 am & 0.680 & 0.327 & 0.281 & 0.246 & 1.000 & & & \\
\hline Index & $10: 30 \mathrm{am}$ & 0.111 & 0.598 & 0.406 & 0.395 & 0.206 & 1.000 & & \\
\hline \multirow[t]{2}{*}{ Signal } & 1:00 pm & 0.134 & 0.477 & 0.692 & 0.606 & 0.200 & 0.685 & 1.000 & \\
\hline & 2:00 pm & 0.095 & 0.425 & 0.593 & 0.707 & 0.178 & 0.638 & 0.850 & 1.000 \\
\hline
\end{tabular}

Note: General statistics of two intraday signals with four representative timings in the tested data are presented. The minimum, mean, median, maximum, and standard deviation are shown in panel A. The correlation coefficients of each pair are given in panel B.

The statistics of the two intraday signals are summarized in Table 1. For the purposes of illustration, we choose four representative timings for $m$ : 9:30 am (the opening time of a trading day), 10:30 am (the mid-time in the morning session), 1:00 pm (the opening time in the afternoon session), and 2:00 pm (the mid-time in the afternoon session). The market closes at 3:00 pm. For every day and chosen $m$, IS and UDS are calculated based on (1) and (2). The minimum, mean, median, maximum, and standard deviation for each chosen $m$ are shown in panel A. The correlation coefficients of each pair of two different times and two signals are given in panel B.

Given the daily price fluctuation limitation of $10 \%$ in the Chinese stock markets, the IS is limited between -0.1 and 0.1 . As shown in Table 1 , there are extreme UDS for each chosen $m$, indicating the extraordinary market situations when all the stocks are rising or falling at the same time. Meanwhile, IS is located in between 0.1 and -0.1 , and the mean and median are close to zero, while UDS is always different from zero. Note that the standard deviation of UDS (about 0.55 for an interval of $[-1,1]$ ) is larger than that of IS (about 0.01 for an interval of $[-0.1$, 0.1]). Although the intraday correlations between the two signals at the same time are about 0.65 (between 0.598 and 0.707), they deliver different, even opposite signals between index and stock movements. In particular, when the IS is near zero, which suggests no significant change in the index level, UDS can be very positive or negative. 


\subsection{Intraday Predictors and Subsequent Return}

Under the efficient market hypothesis (EMH), market price should fully reflect all past price information. This implies that any price information, such as past return, volume, or price, should not predict the future stock or market return (Fama (1970)). As a result, the intraday predictors should not significantly predict the future returns, including intraday returns. We conduct a simple prediction model to examine if the intraday signals have any explanatory power on the subsequent intraday returns,

$$
\text { IntradayReturn }_{m \rightarrow \text { indexd }, t}^{\text {index }}=\alpha_{m}+\beta_{m} \text { Signal }_{m, t}+\varepsilon_{m, t},
$$

where Signal $_{m, t}$ represents either UDS or IS at the intraday time $m$ of day $t$, and IntradayReturn $n_{m, t}^{\text {index }}$ represents the market index return from time $m$ to the market closing, calculated by

$$
\text { IntradayReturn } n_{m \rightarrow e n d, t}^{\text {index }}=\frac{\text { index }_{\text {end }, t}}{\text { index }_{m, t}}-1 .
$$

That is, for any given intraday minute $m$, say 9:45 am, across all the trading days, we calculate the intraday signals, IS and UDS, at 9:45 am and the subsequent intraday index returns from 9:45 am to 3:00 pm. We then run regression (3) between the intraday signals at 9:45 am and the intraday index returns from 9:45 am to 3:00 pm across all the trading days over the 16-year data period. The predictive ability of the intraday signals at each minute on the subsequent intraday market index returns is then characterized by coefficient $\beta_{m}$. We consider every possible $m(9: 31-11: 30 \mathrm{am} ; 1: 01-2: 59 \mathrm{pm})$ in the regression analysis and report the results in Fig. 1 .

In Fig. 1, the $\mathrm{R}^{2}$ and $\mathrm{t}$-statistic of the two intraday signals are reported in Panels $A$ and $B$, respectively. The blue bars in panel A represent the $\mathrm{R}^{2}$ of the regression of the UDS on the intraday return at every minute, and the orange bars represent the $\mathrm{R}^{2}$ of the IS. Panel A shows that both signals have significant predictive power to the subsequent intraday index returns; except for the first 10 minutes in the morning session and the first half-hour in the afternoon session, the two signals explain above $1 \%$ variance of the intraday index return. Interestingly, the $\mathrm{R}^{2}$ is higher for UDS than for IS. Intuitively, while UDS only reflects the aggregate moving direction of the stock prices, IS contains more market information including individual stock return, and hence should be more informative. However, we find that for most of the trading time, the $\mathrm{R}^{2} \mathrm{~s}$ for UDS are higher than that for IS. This implies that the intraday ups and downs of the overall stocks have more explanatory power on the subsequent intraday index returns than the intraday signals of the index itself.

We are also interested in whether the intraday signals explain the intraday returns positively or negatively. To examine the direction of the predictions, we report the t-statistics in panel B. As in panel A, UDS is represented by the blue bars and IS by the orange bars. Except for the first 4 minutes in the morning session, the early intraday signals predict the subsequent index intraday returns significantly for most of the subsequent time; the t-statistics of the two signals are greater than 4, which provide strong evidence of the positive relation between the intraday indicators and the subsequent intraday market returns. The predictive power is maintained at a similar level in the morning session; with $\mathrm{R}^{2}$ of $1 \%-2 \%$ and t-statistics of $6-9$ for IS, and $\mathrm{R}^{2}$ of $2 \%-2.5 \%$ and $\mathrm{t}$-statistics of $8-10$ for UDS. In the afternoon session, the prediction power first decreases and then increases. Therefore, the intraday signals positively and significantly predict the subsequent intraday market returns. 

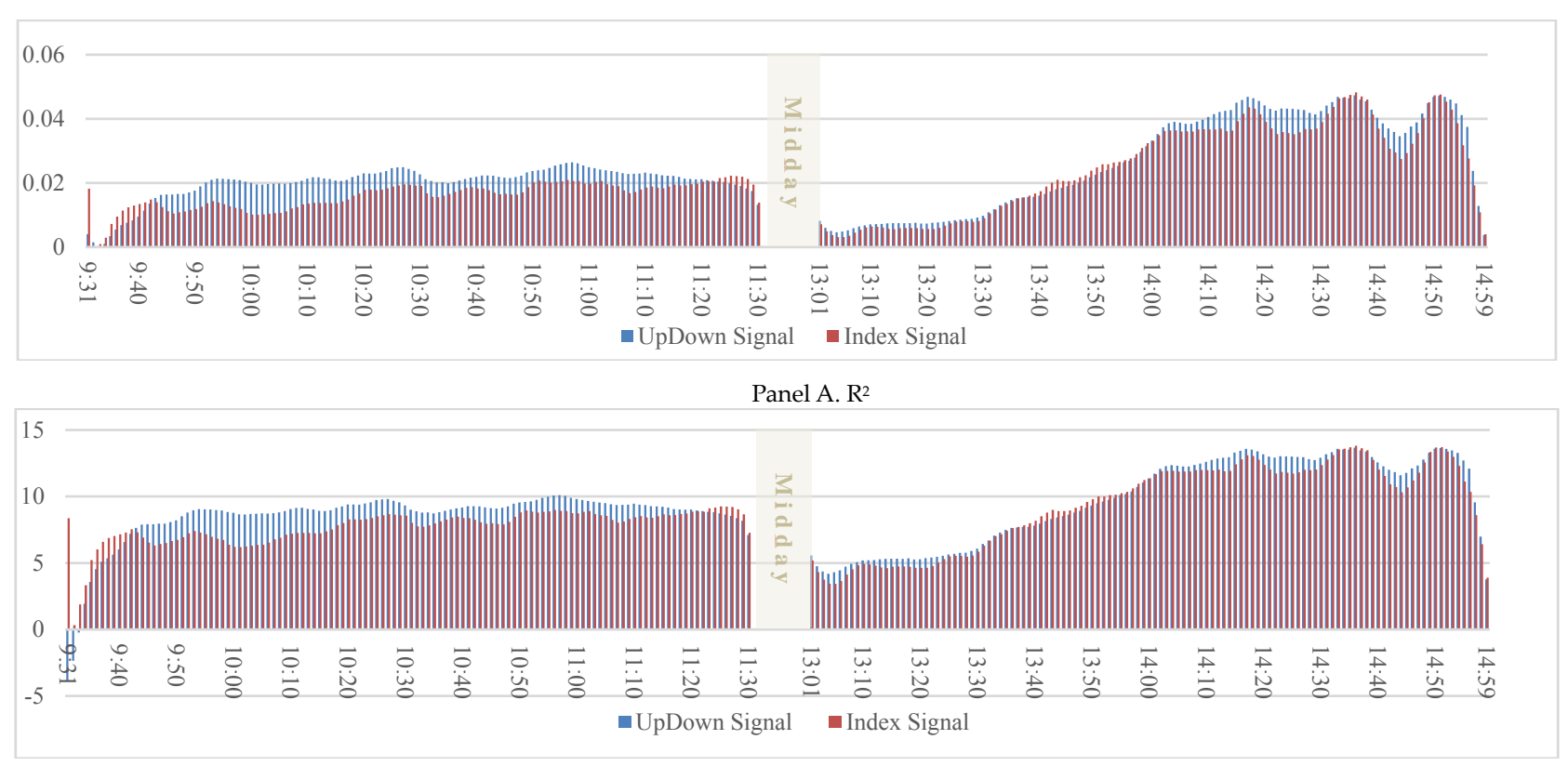

Panel B. T-statistics

Fig. 1 Intraday Return Predictive Ability of Every Minutes Signal

Note: We regress the subsequent intraday market return every minute on the intraday signal, IntradayReturn $n_{m \rightarrow e n d, t}=$ $\alpha_{m}+\beta_{m}$ Signal $_{m, t}+\varepsilon_{m, t}$. Two types of signals, UpDown Signal (UDS) and Index Signal (IS), are considered. Every single minute between the trading hours (9:31-11:30 am; 1:01-2:59 pm) are chosen as $m$. The $\mathrm{R}^{2} \mathrm{~s}$ are reported in panel A and $\mathrm{t}$ statistics are reported in panel B. The blue bars and orange bars in both panel represent the UDS and IS, respectively. Our sample period is from Jan. 2000 to Aug. 2015 (3769 trading days) and all firms listed in SHSE or SZSE are considered for the UDS.

To conclude, we note that, as $m$ increases, the predicting period of the intraday returns shrinks. For example, when $m$ is 10:00 am, the predicted intraday returns are over the next 3.5 hours. When $m$ is 2 pm, only the intraday return of the remaining one hour is predicted. Clearly, the longer is the remaining trading period, the more difficult is the prediction. This also explains the increase in $\mathrm{R}^{2}$ when $m$ is close to the end of the trading day.

\subsection{A Simple Trading Strategy Based on Intraday Signals}

Two key questions emerge from the results above: First, is the predictive ability of the intraday signals economically significant? The $\mathrm{R}^{2}$ and $\mathrm{t}$-statistic show the statistical significance of the signals, but this does not necessarily indicate the economic significance. Second, how should the intraday predictions for different $m$ values be compared? As we have discussed, a different $m$ value suggests a different subsequent intraday return; a simple comparison of the $\mathrm{R}^{2}$ and $\mathrm{t}$-statistics shows a disadvantage for the intraday return prediction over longer intraday time horizons.

Based on the positive relation between the intraday indicators and the subsequent intraday market returns, we introduce signal-based intraday trading strategies to examine these two questions. It is a simple and intuitive strategy that longs (or shorts) the index and keeps the position to the end of the trading day when the early intraday signal is positive (negative). Correspondingly, we define the daily strategy return by 


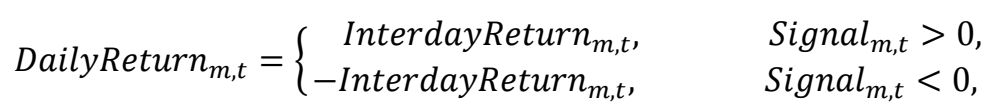

where DailyReturn $n_{m, t}$ represents the intraday return of the strategy based on Signal $_{m, t}, m$ is can be any minute in the trading day, and $t$ is any day in our sample period. InterdayReturn $n_{m, t}$ is given in (4). The intraday trading strategy is applied to the SHSECI with a sample period of over 3,769 trading days and the intraday strategy return is calculated for every possible $m$. As in Fig. 1, we report the basis points (BPs) of the average intraday strategy return and the corresponding t-statistics in Fig. 2.
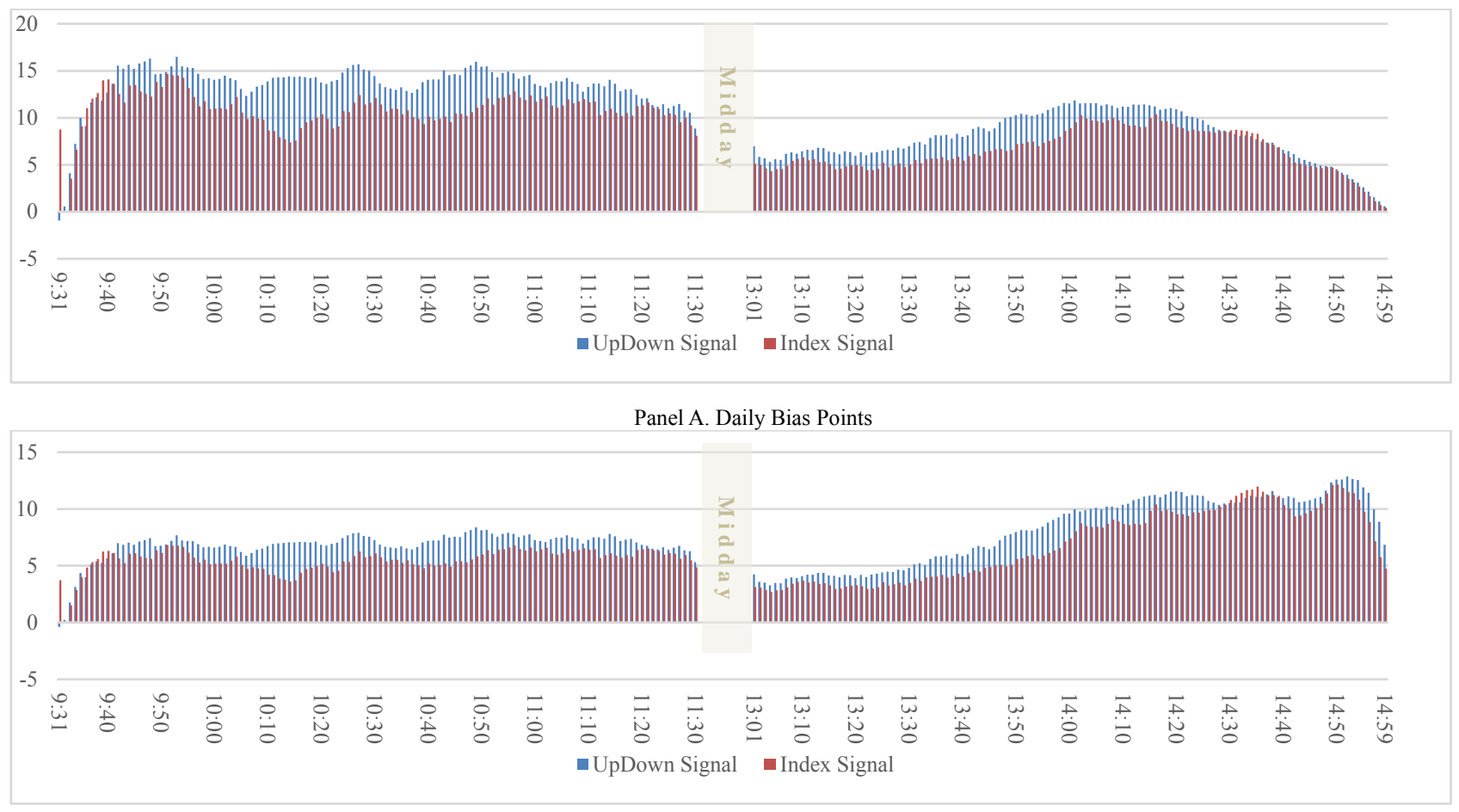

\section{Panel A. T-statistics}

Fig. 2 Daily Basis points of the Signal-based Trading Strategy

Note: We build a simple strategy based on the intraday signals at time $m$ of day $\mathrm{t}$ by taking long (short) position in SHSECI when the signal is positive (negative) and hold the position to the end of day $t$. The signal is either UDS or IS. Timing $m$ is every minute between the trading hours (9:31-11:30 am; 1:01-2:59 pm). The average returns and their $t-$ statistics are reported in panels A and B, respectively. The blue bars in both panels represent the UDS and the orange ones represent the IS. The sample period is from Jan. 2000 to Aug. 2015 (3,769 trading days) and all the firms listed in SHSE or SZSE are considered when we build the UDS.

In Fig. 2, the blue and orange bars represent the statistical result of the two different signals at each $m$. The average BPs of the intraday trading profit are reported in panel A and their $\mathrm{t}$-statistics are reported in panel B. The results indicate that the strategy returns with most $m$ are positive at the $95 \%$ level of significance, except the first 3 minutes in the morning session. The strategies based on UDS lead to about 16 BPs average daily return, especially between the 9:40-9:50 am, which means a 50\% annualized return exclusive of transaction cost. If we consider the transaction cost in the Chinese stock markets, the general one-time transaction fee of stocks is $0.025 \%$ of trading value, which means the buy-sale trading costing is about 5 BPs. 
It is significantly smaller than the return of our strategy. Furthermore, a lower transaction cost is obtained by trading in an index future that has a trading fee of $0.003 \%$. Hence, the strategy return of the intraday signal is economically significant ${ }^{1}$.

One interesting observation is that the strategy returns based on UDS are higher than the strategy returns based on IS. One may argue that the intraday return pattern discovered in this study is because of the high information-relative elements contained in our signal and the under-reaction of investors to information. However, if the predictive abilities of the intraday signals come from the information components, the prediction abilities of IS should be better than that of UDS. This is because the information included in IS is a size-weighted sum of individual stock returns, while UDS is simply an equal-weighted sum of the directions of stock up/down movements. However, the results in Figures 1 and 2 show that the relatively less informative signal, UDS, predicts the subsequent intraday return better. This is inconsistent with the information underreaction hypothesis. This pattern also suggests that investors are affected more by the individual stock movements on which they are focused.

Comparing the strategy returns for different $m$ values, as indicated in Fig. 2, although the accuracy of the intraday trading strategy in one hour before the market close is higher (with higher t-statistic), its performance is lower than the one in the morning sessions. In particular, after 2:30 pm, the profits of the intraday trading strategy are falling, though the t-statistic is increasing. The highest intraday trading strategy returns are achieved between 9:40 am and 11:00 am. In addition, the UDS-based strategies are about 14 BPs, which is about 3 BPs higher than the IS-based strategies, and both of them are highest between 9:40 am and 11:00 am as compared to the strategy returns of other intraday trading strategies.

\subsection{Time-Series Performance of the Signal Strategy}

To further explore the prediction power of the intraday signals, a time-series analysis about the performance of the signal-based intraday strategies is conducted in this section. We compare the performance of two signal strategies to passively holding the SHSECI strategy in the corresponding period. At time $m$ of everyday, we observe the UDS or IS signals, and take the long position (with positive signal) or the short (with negative signal) position in the SHSECI using all the capital, and hold the position to the end of the trading day. The accumulative wealth of each strategy is recorded during our sample period. Without loss of generality, we choose $m$ between 10:01 am and 11:00 am and average their returns to obtain the daily return.

$$
\text { avDailyReturn }_{t, I}=\sum_{m=10: 01}^{11: 00} \text { DailyReturn }_{t, m, I} / 60,
$$

where $I$ is either UDS or IS and DailyReturn $n_{t, m, I}$ is calculated based on (5). The starting capital is one dollar, which is successively invested in the trading strategy based on UDS, IS, and the passive market buyand-hold strategy during our sample period. To expound a tradable strategy, the daily strategy returns of a representative timing, 10:30 am, are given as well. The performance of the five strategies is reported in Fig. 3.

\footnotetext{
1 Ideally, as suggested by the referee, we would like to apply our strategy to the index future from 2010. However, we are unable to obtain the intraday index future data from the "Wind" database, or from anywhere else.
} 


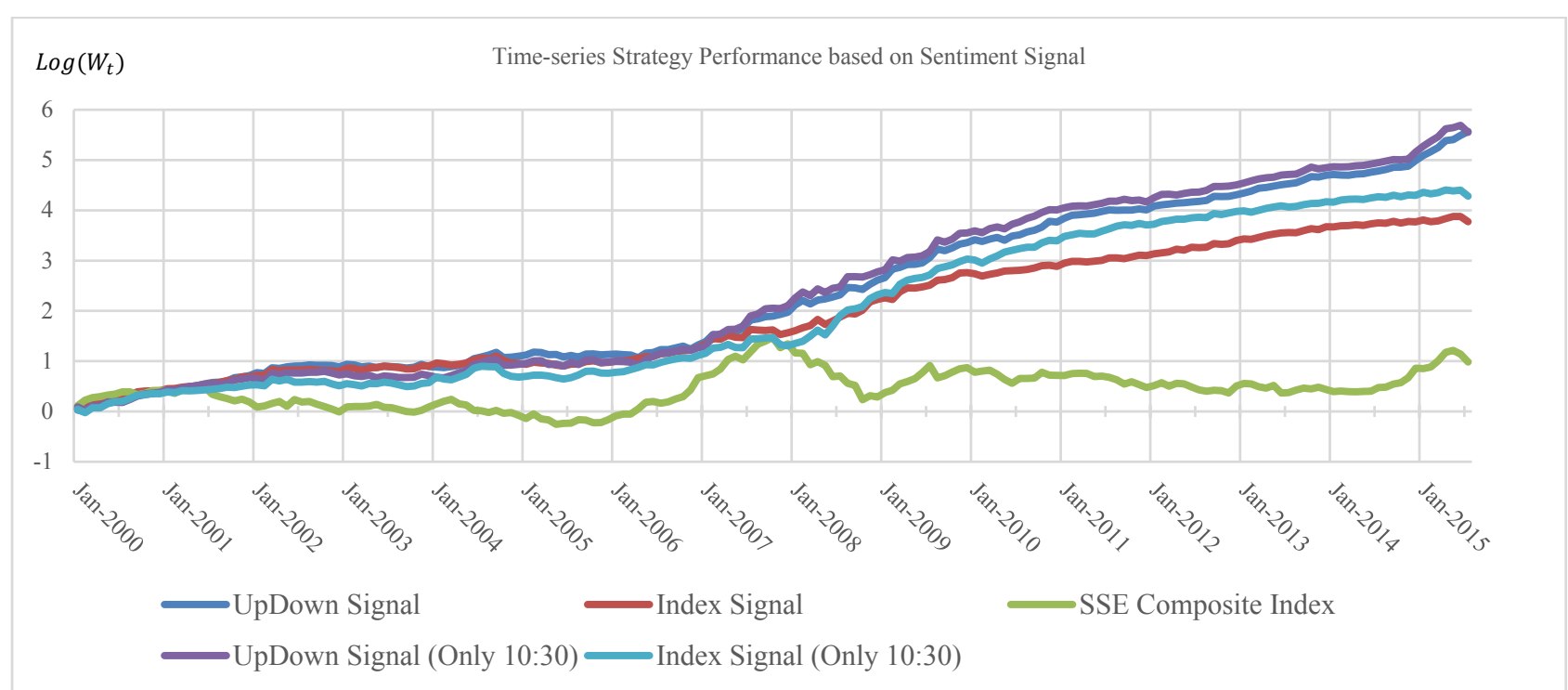

Fig. 3 Time-series Strategy Performance

Note: We simulate the investment return of one dollar and keep investing in the strategy from Jan. 2000 to Aug. 2015. Two types of signals are considered, UDS and IS. The passive market return based on the SHSECI is treated as a benchmark. We use the average returns from 10:01 am to 11:00 am as our daily strategy return. The logarithm of wealth of each strategy are shown. The blue and orange lines show the wealth change of the strategy based on UDS and IS, respectively. The grey line shows the value of the SHSECI. On the other hand, a representative timing, 10:30 am, is chosen to report tradable results, which are described in yellow (UDS) and dark blue (IS) line.

In Fig. 3, the blue, orange, gray, yellow, and dark blue lines represent the average UDS, average IS, passive market, 10:30 am UDS, and 10:30 am IS strategies, respectively, and the changes in the logarithm of wealth are reported based on the continuing investment. It shows that the returns of the two signal-based trading strategies are obviously higher than the passive market strategy. The logarithm of wealth of the USD- and ISbased strategies is continuously accumulated without any huge decline in both the average case and the representative case. In the long-term, the greater predictive ability of UDS is also confirmed in Fig. 3. This implies that the predictive ability of the intraday signals on the intraday market return is very persistent.

In summary, the intraday market-wide up and down movement signals based on the index and overall stocks predict the subsequent intraday market returns for most minutes in trading day (except the first 4 minutes). The predictive ability is both economically and statistically significant. This ability is maintained in the morning sessions, and increases as the time approaches the end of the trading day. A simple intraday trading strategy based on the prediction of the intraday signals shows that the performance of the intraday pattern is highly significant over the sample period and is even better in the morning sessions. Furthermore, the UDS-based trading strategy performs better than the IS strategy for most $m$.

\section{Potential Explanations of the Intraday Pattern}

One potential explanation of the intraday market returns is the intraday sentiment of naïve individual investors. The past stock return is considered as a sentiment signal in several theoretical studies (Barberis et al. (2015), Barberis et al. (1998)). However, due to its complicated components, it is difficult to separate the 
sentiment from the past returns. For these reasons, we first examine several possible explanations and then conclude that the intraday sentiment of individual investors is a more convincing explanation.

One of the primary concerns among several potential explanations of the intraday return pattern examined in this section is the $\mathrm{T}+1$ and short-sale constraints, which characterize the Chinese stock markets. Moreover, the excessive systemic risk-taking is another important factor, and the intraday trading strategy could be a beta-strategy without capturing any anomaly. Our time-series and cross-section analysis results do not provide evidence of these two explanations. Finally, by using different measures on the activity of individual investors, we show that the intraday trading strategy returns based on the intraday return patterns become more significant when investors are more active in the market. Therefore, the prediction power of the early intraday up/down signals is more likely driven by the intraday sentiment of individual investors who believe that the early intraday market-wide movements will continue to the end of the trading day.

\subsection{The Intraday Strategy Return and Short-Sale Constraints}

The intraday trading strategy returns could be driven by the " $\mathrm{T}+1$ " trading rule and short-sale constraints in the Chinese stock markets. As an emerging market, these constraints are remarkable features of the Chinese stock markets. The "T+1" trading rule prohibits investors to sell stock they have bought on the same day. From March 2010, both SHSE and SZSE allowed securities margin trading for individual investors. However, the extremely high transaction costs, capital requirements, and limited stocks make short-sale almost impossible in the Chinese markets. Other financial derivatives, such as index ETF and index futures, were not allowed in China before 2010. Therefore, if the returns of the intraday trading strategies are primarily from short trading, they may be due to the trading friction in the imperfect Chinese markets.

To examine the impact of the short sales, we separate the intraday strategy return based on the directions of the UDS signals. When the signal is positive (negative), which suggests that the trading position is long (short), we classify the intraday strategy return as "long (short)-leg" statistics; otherwise, the strategy returns are named "double" (taking both long and short positions when the USD is positive and negative, respectively). For each case, we report several statistical properties, including mean, median, standard deviation, and the t-statistic of the basis points (BPs). We also report the sample size for each case and the probability of the UDS correctly predicts the subsequently intraday return.

The all-sample results are reported in Panel A of Table 2. Without loss of generality, we choose each minute $m$ between 10:01 am and 11:00 am. Since the direction of the UDS signal for each $m$ in the same day could be different, we implement the UDS strategy for every single $m 60$ times in every day, except when the signal equals 0 . The sample date is from January 2000 to June 2015, which provides data for 3,769 trading days. The "long-leg" and "short-leg" columns report the results of the long-only and short-only trading, respectively, while the "double" column reports the results of both long and short trading. We also consider different time intervals, different intraday time, and three representative timings, the results of which are reported in Panels B and C. In each sub-sample result, the "double", "long-leg" and "short-leg" strategies are reported from left to right, respectively. 
Table 2. The UpDown Signal Strategy Performance

\begin{tabular}{|c|c|c|c|}
\hline \multicolumn{4}{|c|}{ Panel A: Jan. 2000-Jun. 2015 (10:01-11:00 am) } \\
\hline & Double & Long leg & Short leg \\
\hline Mean & 14.45 & 26.09 & 5.75 \\
\hline Median & 12.58 & 24.78 & 3.09 \\
\hline SD & 121.75 & 114.98 & 125.89 \\
\hline T statistics & 56.34 & 70.44 & 16.41 \\
\hline Accuracy (\%) & 55.96 & 61.94 & 51.48 \\
\hline Sample & 225,286 & 96,399 & 128,887 \\
\hline
\end{tabular}

Panel B: Different Daily Periods (10:01-11:00 am)

\begin{tabular}{|c|c|c|c|c|c|c|c|c|}
\hline \multicolumn{3}{|c|}{ Jan. 2000-Dec. 2004} & \multicolumn{3}{|c|}{ Jan. 2005-Dec. 2009} & \multicolumn{3}{|c|}{ Jan. 2010-Jun. 2015} \\
\hline Double & Long leg & Short leg & Double & Long leg & Short leg & Double & Long leg & Short leg \\
\hline 8.97 & 15.17 & 4.89 & 17.97 & 36.5 & 4.40 & 16.11 & 26.13 & 7.87 \\
\hline 8.65 & 14.20 & 4.61 & 17.19 & 40.53 & -3.84 & 13.34 & 23.60 & 5.38 \\
\hline 99.61 & 95.67 & 101.92 & 152.19 & 138.67 & 160.28 & 107.72 & 105.22 & 109.09 \\
\hline 24.03 & 26.66 & 9.94 & 31.88 & 45.95 & 5.59 & 42.61 & 47.48 & 15.18 \\
\hline 54.41 & 57.25 & 52.53 & 55.80 & 65.34 & 48.64 & 57.46 & 62.66 & 53.13 \\
\hline 71,226 & 28,268 & 42,958 & 72,857 & 31,254 & 41,603 & 81,203 & 36,877 & 44,326 \\
\hline \multicolumn{9}{|c|}{ Panel C: Different Intraday Timing (Jan. 2000-Jun. 2015) } \\
\hline \multicolumn{3}{|c|}{ 10:01-10:20 am } & \multicolumn{3}{|c|}{ 10:21-10:40 am } & \multicolumn{3}{|c|}{ 10:41-11:00 am } \\
\hline Double & Long leg & Short leg & Double & Long leg & Short leg & Double & Long leg & Short leg \\
\hline 13.91 & 24.27 & 5.96 & 14.25 & 25.36 & 5.90 & 15.20 & 28.70 & 5.40 \\
\hline 12.55 & 22.42 & 4.39 & 12.61 & 25.43 & 3.18 & 12.55 & 26.38 & 1.47 \\
\hline 126.50 & 120.87 & 130.10 & 121.61 & 115.38 & 125.45 & 116.98 & 108.09 & 122.10 \\
\hline 30.13 & 36.25 & 9.45 & 32.12 & 39.46 & 9.74 & 35.61 & 47.19 & 9.23 \\
\hline 55.89 & 60.58 & 52.29 & 55.92 & 61.85 & 51.46 & 56.07 & 63.45 & 50.72 \\
\hline 75,100 & 32,593 & 42,507 & 75,097 & 32,226 & 42,871 & 75,089 & 31,580 & 43,509 \\
\hline
\end{tabular}


Table 2. Cont.

\begin{tabular}{|c|c|c|c|c|c|c|c|c|}
\hline \multicolumn{9}{|c|}{ Panel D: Representative Tradable Timing (Jan. 2000-Jun. 2015) } \\
\hline \multicolumn{3}{|c|}{ 10:00 am } & \multicolumn{3}{|c|}{$10: 30$ am } & \multicolumn{3}{|c|}{ 11:00 am } \\
\hline Double & Long leg & Short leg & Double & Long leg & Short leg & Double & Long leg & Short leg \\
\hline 13.55 & 24.84 & 4.75 & 14.66 & 25.68 & 6.31 & 14.14 & 28.03 & 4.16 \\
\hline 12.70 & 22.23 & 4.17 & 12.43 & 24.14 & 3.41 & 14.20 & 26.81 & 0.00 \\
\hline 130.00 & 125.47 & 132.79 & 122.04 & 117.49 & 124.76 & 114.84 & 102.73 & 121.86 \\
\hline 6.39 & 8.03 & 1.64 & 7.36 & 8.79 & 2.34 & 7.54 & 10.80 & 1.60 \\
\hline 56.18 & 61.03 & 52.39 & 55.75 & 61.50 & 51.40 & 55.85 & 64.09 & 49.93 \\
\hline 3,769 & 1,652 & 2,117 & 3,769 & 1,625 & 2,144 & 3,769 & 1,575 & 2,194 \\
\hline
\end{tabular}

Note: We calculate the Single-based strategy return of holding only long, short, or both side positions, respectively. The trading strategy is to take long (short) position in the market index (SHSECI) when the UDS is positive (negative) at time $m$ to the close of the today. When the UDS equal 0, we do not trade. Panel A reports the strategy returns of overall sample from Jan. 2000 to Jun. 2015 when $m$ is between 10:01 am to 11:00 am. The "Double" column gives the return statistics of double side trading. The "Long (Short)" column report the result only trading when the signal is positive (negative). The first four lines report the mean, median, standard deviation, and t-statistic of the daily returns in basis points. The fifth line gives the probability when the signals correctly predict the daily returns. The sixth line gives the total trading times for each case. Panel B reports the results for 3 different daily periods, Jan. 2000 to Dec. 2004, Jan. 2005 to Dec. 2009 and Jan. 2010 to Jun. 2015. Panel C reports 3 different selections of intraday $m, 10: 01 \mathrm{am}$ to 10:20 am, 10:21 am to 10:40 am, and 10:41 am to 11:00 am. Panel D reports 3 representative timing, 10:00 am, 10:30 am, and 11:00 am. For each sub-panel, the "Double", "Long leg" and "Short leg" column are reported from left to right.

The results in Table 2 show that the strategy returns are primarily from the long side trading, independent of the sample periods, time periods, and the choice of $m$. For example, for the entire sample, Panel A shows the return of 26.09 BPs in the long-only strategy and 5.75 BPs in the short-only strategy, while the return is 14.45 BPs for the long and short strategy. This implies that the strategy returns do not vanish with the shortsale constraint.

In fact, the strategy returns are partially affected by the short-sale constraint. Before 2010, both the SHSE and the SZSE introduced the index future and security lending transactions to individual investors and made the short sale possible. However, after introducing the short-sale constraint in 2010, the short-only strategy returns increased from 4.40 BPs to 7.87 BPs, while the long-only strategy returns dropped marginally (from 36.5 BPs to 26.13 BPs, see Panel B). This implies that the short-sale constraint decreases, instead of increasing, the same side profits.

More importantly, the returns for the long-only strategies are much higher than for the long-and-short strategies, which suggest that the profits of the intraday strategies become more significant under the shortsale constraint. One possible explanation is that, when an investor receives a negative signal, he can only sell the stocks held by him; otherwise, he cannot take a short position by reacting to the negative signal. However, when he receives a positive signal, he can always take long positions. This asymmetrical trading behavior induces asymmetrical intraday market returns. When the short sale constraint is allowed, the short trading following a negative signal increases the return of the short leg, which reduces the return of the long leg. With 
the short-sale constraint, the strategy returns of the long side trading become more significant.

Another possible reason of asymmetrical strategy return is the " $\mathrm{T}+1$ " trading rule. The " $\mathrm{T}+1$ " rule does not allow investors to adjust their positions by selling the stocks they just bought, even if their earlier buying decisions were driven by positive intraday that are subsequently proved to be wrong. On the contrary, if investors realize that an early short-position based on negative sentiment-driven decision is incorrect, they can correct their earlier mistakes by longing the stock later. Clearly, the index future and securities lending transactions also weaken the asymmetrical impact of the " $\mathrm{T}+1$ " rule.

In Panel C and Panel D, the strategy returns for different $m$ indicate that there is no significant difference among the three time intervals or three representative timings, though the means increase and variance decrease slightly as $m$ increases.

In summary, by examining the long-only and short-only strategy returns with different time periods over different intraday times, we do not find evidence to support the hypothesis that the intraday strategy returns are due to the $\mathrm{T}+1$ rule or short-sale constraints. More importantly, the long-only strategy returns constitute the main part of the intraday strategy returns. In fact, due to the short sale constraint and " $\mathrm{T}+1$ " trading rule, the impact from the earlier intraday market movements is maintained in the subsequent intraday return. Allowing short sale enlarges the short-leg returns and shrinks the long-leg returns.

\subsection{Strategy Return and Systematic Risk}

Another concern about the intraday strategy returns is the systematic risk factor. The return could be driven by overloading the systematic risk, making the strategy a beta strategy without any abnormal return (Alpha). We introduce the classical Fama-French three factor model (Fama and French $(1992,1993,1996))$ to minimize the system risk component in the strategy returns. We are not concerned about a high loading of the market returns since both the long and short positions based on the intraday signals of the market returns are about the same (see Panel A in Table 1). It is likely that they cancel each other in the market loading. The unpredictable parts are the loadings for SMB (Small Minus Big for size portfolio) and HML (High Minus Low for value portfolio), which are driven by the returns of the firms with different characteristics. The abnormal return is potentially caused by the intraday signals that capture an element highly related to the size effect or $\mathrm{B} / \mathrm{M}$ effect.

We follow Fama and French (1996) and obtain the three daily and monthly factors from the "Resset" database. We regress them on the intraday strategy returns,

$$
\text { StrategyReturn }_{t}=\text { Alpha }+\beta_{M R} \text { MarketReturn }_{t}+\beta_{S M B} S M B_{t}+\beta_{S M L} H M L_{t}+\varepsilon_{t},
$$

where the StrategyReturn is calculated by (6) with the UDS. Regression is conducted at both daily and monthly levels. Monthly strategy returns are computed by rescaling the daily strategy returns. Due to the incomplete daily holding, we use the intraday market returns, MarketReturn min $\rightarrow$ end,t $_{\text {to }}$ to measure the daily MarketReturn $_{t}$. Three different minutes ( $\mathrm{min}$ ) are used to match the trading strategy holding periods, namely, 10:01 am, 10:31 am, and 11:01 am.

We report the results in Table 3. Panel A reports the regression on the long-only, short-only, and longand-short strategy returns. The independent variables are Market return, SMB, and HML. The estimates of each variable and its t-statistic are reported, together with the sample size and $\mathrm{R}^{2}$. Time intervals are daily and

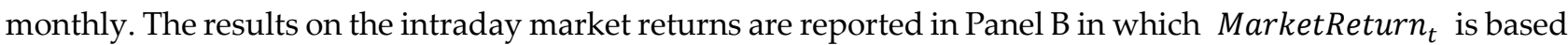




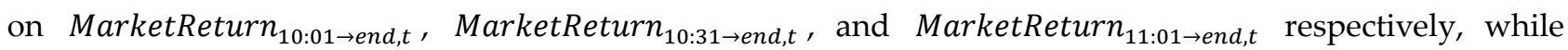
the $S M B_{t}$ and $H M L_{t}$ are the same.

Table 3. Risk-adjust Alpha of UpDown Signal Strategy

\begin{tabular}{|c|c|c|c|c|c|c|}
\hline \multicolumn{7}{|c|}{ Panel A. FF 3 Factors with Daily Market Return } \\
\hline & \multicolumn{2}{|c|}{ Long leg } & \multicolumn{2}{|c|}{ Short leg } & \multicolumn{2}{|c|}{ Double } \\
\hline & Daily & Monthly & Daily & Monthly & Daily & Monthly \\
\hline \multirow[t]{2}{*}{ Alpha } & $0.0010^{c}$ & $0.0202^{c}$ & $0.0006^{c}$ & $0.0086^{c}$ & $0.0016^{c}$ & $0.0292^{c}$ \\
\hline & $(11.6152)$ & $(11.7705)$ & $(5.5563)$ & $(4.1819)$ & $(9.8005)$ & $(8.3890)$ \\
\hline \multirow[t]{2}{*}{$M . R$. } & $0.2479 \mathrm{c}$ & $0.2421^{c}$ & $-0.3281^{c}$ & $-0.1827^{c}$ & $-0.0802^{c}$ & 0.0566 \\
\hline & $(47.5939)$ & $(11.9275)$ & $(-51.8588)$ & $(-7.5561)$ & $(-8.2186)$ & $(1.3747)$ \\
\hline \multirow[t]{2}{*}{$S M B$} & $-0.0841^{c}$ & -0.0012 & 0.0012 & $0.1633^{c}$ & -0.0829 c & $0.1688^{\text {a }}$ \\
\hline & $(-6.0626)$ & $(-0.0274)$ & $(0.0717)$ & (3.1174) & $(-3.1889)$ & $(1.8927)$ \\
\hline \multirow[t]{2}{*}{$H M L$} & $-0.0665^{c}$ & 0.0709 & $-0.1060^{c}$ & 0.0363 & $-0.1725^{c}$ & 0.1107 \\
\hline & $(-3.7928)$ & $(1.2129)$ & $(-4.9786)$ & $(0.5218)$ & $(-5.2515)$ & $(0.9341)$ \\
\hline Sample Size & 3769 & 187 & 3769 & 187 & 3769 & 187 \\
\hline \multirow[t]{4}{*}{$R^{2}$} & 0.3812 & 0.4615 & 0.4448 & 0.2517 & 0.0330 & 0.0377 \\
\hline & \multicolumn{4}{|c|}{ Panel B. FF 3 Factors with Intra-Day Market Return } & & \\
\hline & \multicolumn{2}{|c|}{ Long leg } & \multicolumn{2}{|c|}{ Short leg } & \multicolumn{2}{|c|}{ Double } \\
\hline & Daily & Monthly & Daily & Monthly & Daily & Monthly \\
\hline \multirow[t]{2}{*}{ Alpha } & $0.0008^{c}$ & $0.0150^{c}$ & $0.0010^{c}$ & $0.0132^{c}$ & 0.0017 c & $0.0287 \mathrm{c}$ \\
\hline & (10.0438) & $(8.5024)$ & (11.5213) & $(6.5353)$ & (10.4228) & (7.8597) \\
\hline \multirow[t]{2}{*}{$M . R_{10: 01 \rightarrow \text { end }}$} & $0.3590^{c}$ & 0.4289 c & $-0.6003^{c}$ & $-0.3688^{c}$ & $-0.1534^{c}$ & 0.0554 \\
\hline & $(55.6965)$ & (12.3578) & $(-78.7767)$ & $(-9.3079)$ & $(-12.0216)$ & $(0.7725)$ \\
\hline$R^{2}$ & 0.4566 & 0.4783 & 0.6406 & 0.3337 & 0.0521 & 0.0310 \\
\hline \multirow[t]{2}{*}{ Alpha } & $0.0008^{c}$ & $0.0147^{c}$ & 0.0009 c & $0.0146^{c}$ & $0.0017^{c}$ & $0.0298^{c}$ \\
\hline & $(10.2601$ & $8.0571)$ & (10.4273) & $(7.9006)$ & $10.5268)$ & $(8.1040)$ \\
\hline \multirow[t]{2}{*}{$M . R_{10: 31 \rightarrow \text { end }}$} & $0.3894^{c}$ & $0.4692^{c}$ & $-0.5735^{c}$ & $-0.4852^{c}$ & $-0.1840^{c}$ & -0.0238 \\
\hline & (57.3583) & (11.6944) & $(-81.8682)$ & $(-11.9180)$ & $(-13.5768)$ & $(-0.2935)$ \\
\hline$R^{2}$ & 0.4711 & 0.4523 & 0.6576 & 0.4473 & 0.0616 & 0.0283 \\
\hline
\end{tabular}


Table 3. Cont.

\begin{tabular}{|c|c|c|c|c|c|c|}
\hline \multicolumn{7}{|c|}{ Panel B. FF 3 Factors with Intra-Day Market Return } \\
\hline & \multicolumn{2}{|c|}{ Long leg } & \multicolumn{2}{|c|}{ Short leg } & \multicolumn{2}{|c|}{ Double } \\
\hline & Daily & Monthly & Daily & Monthly & Daily & Monthly \\
\hline \multirow[t]{2}{*}{ Alpha } & $0.0008^{c}$ & 0.0137 c & $0.0010^{c}$ & $0.0172 \mathrm{c}$ & $0.0018^{c}$ & $0.0315^{c}$ \\
\hline & $(9.0002)$ & $(6.6329)$ & $(11.5213)$ & $(9.2087)$ & $(10.8954)$ & $(8.2822)$ \\
\hline \multirow[t]{2}{*}{$M . R_{\cdot 11: 01 \rightarrow \text { end }}$} & $0.3871^{c}$ & $0.4496^{c}$ & $-0.6003^{c}$ & $-0.5577^{c}$ & $-0.2132^{c}$ & -0.1172 \\
\hline & $(51.0201)$ & $(9.2146)$ & $(-78.7767)$ & $(-12.6338)$ & $(-14.8817)$ & $(-1.3046)$ \\
\hline$R^{2}$ & 0.4140 & 0.3462 & 0.6406 & 0.4756 & 0.0704 & 0.0368 \\
\hline
\end{tabular}

Note: The 3 Fama-French factors are used to eliminate the general component systemic risk in our signal-based strategy return. The Market Return, SMB, and HML considered here are formed based on the Fama and French (1997), and the data are obtained from the "Resset" database. The strategy is explained in Table 2 and strategy return in two time-intervals, daily return, and monthly returns, are tested here. "Long leg", "Short leg" and "Double" columns represent the strategy trades on longonly, short-only, and both long-and-short positions, respectively. Without loss of generality, we calculate the daily strategy return based on the average return of $m$ between 10:01 am and 11:00 am. Panel A reports all the regression coefficients, $t$ statistic, and $\mathrm{R}^{2}$. The intraday market return is considered as an alternative measure of market return. We use the intraday returns from 10:01 am, 10:31 am, and 11:01 am to market close (3:00 pm) for daily market returns. The SMB and HML remain the same. The result of substituted M.R. is reported in panel B, and the regression coefficient and t statistic of alpha and alternate M.R. are also reported with $\mathrm{R}^{2}$. The subscripts a, b, c represent the significance levels of $90 \%, 95 \%$, and $99 \%$, respectively.

The estimation of the market returns is consistent with our expectations. The long (short) only strategy has a positive (negative) loading, while the long-and-short strategy return has a smaller negative loading due to short-only trading that is observed more frequently in Table 2 . The $\mathrm{R}^{2}$ of long-and-short regression is small at both daily and monthly levels. The results of SMB and HML are interesting. In the long-and-short regression, their explanatory power is higher at the daily level than at the monthly level, which is not very often observed in the three-factor literature. More interestingly, at the daily level, the coefficients for the SMB and HML are negative, which suggests that the intraday strategy returns are negatively correlated to the size and value effects. Due to the positive mean value and negative coefficients of the three factors, the controlled alpha, 16 BPs, is higher than the uncontrolled return, 14.45 BPs, as is demonstrated in Panel A. The result provides evidence that our intraday strategy returns are not driven by systemic risk and the beta strategy.

The results in Panel B show that calculating the daily return by the intraday market return improves the $\mathrm{R}^{2}$ of the long, short, and double side regressions. The higher $\mathrm{R}^{2}$ does not compare with the lower alpha, because the loading of the double side return stays negative. In contrast, the alpha increases from 16 BPs to 18 BPs and all the alphas reject the null hypotheses under a $1 \%$ level of significance. 


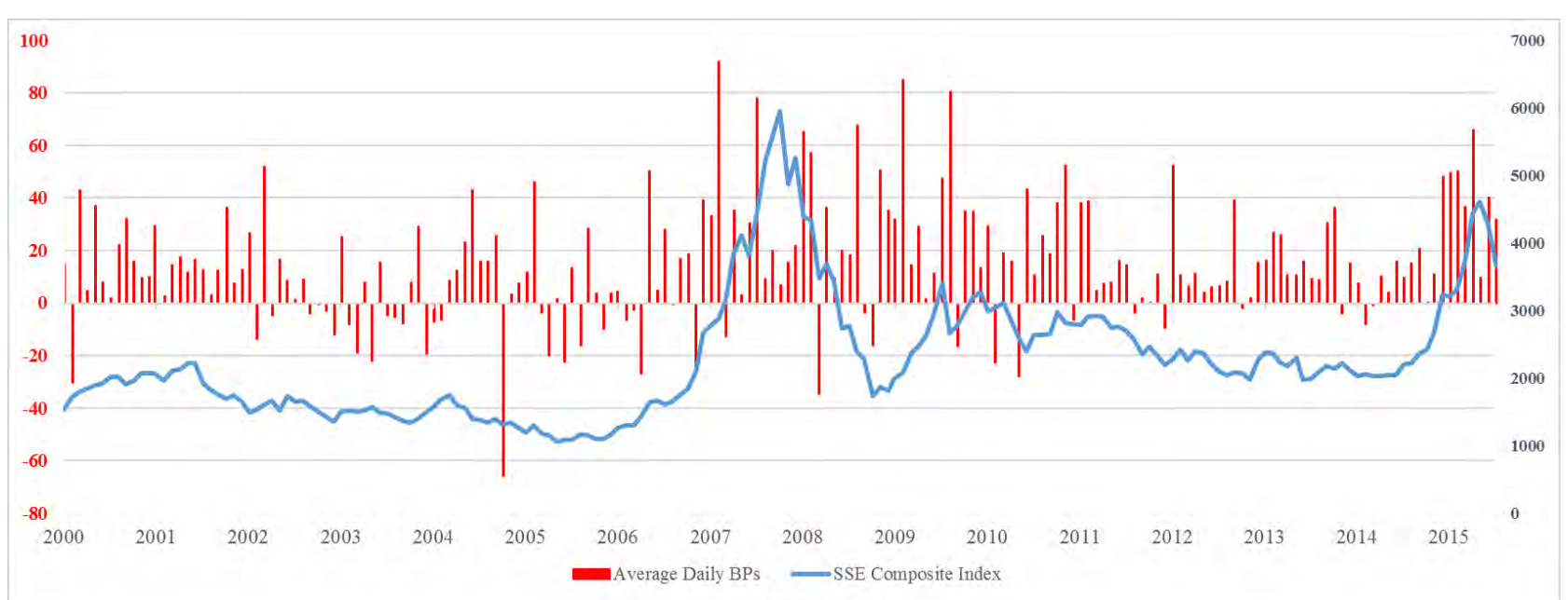

Fig. 4 Shanghai Stock Exchange Composite Index and Average Daily Return of UpDown Signal

Note: The red bars show the average daily strategy returns (BPs) based on the UDS for every month. The daily return is calculated by the average return from 10:01 am to 11:00 am. The blue line represents the Shanghai Stock Exchange Composite Index (SHSECI).

Another concern is how the strategy return is related to the systemic risk. We plot the monthly strategy return and the SHSECI index level in Fig. 4. It shows that in most months, the strategy returns are positive (shown by the red bar). Especially, from 2007 to 2010, and around 2015, the average daily strategy returns are significantly positive, reaching about $60 \mathrm{BPs}$ to $80 \mathrm{BPs}$. Meanwhile, as shown in the SHSECI, the Chinese stock markets experienced huge bubbles and crashes in this period, which indicate that higher market volatility produces a higher sentiment driven return.

We also run a regression of the monthly market volatility on the strategy returns. We measure the monthly market volatility using the standard deviation of the daily market returns. We also use the close to open, open to close, 10:01 am to close, 10:31 am to close, and 11:01 am to close returns as robustness checks. The results reported Table 4 unsurprisingly show that all the volatility measures are significantly and positively related to the strategy returns. If the market-wide up/down intraday signals can predict the subsequent intraday trend, a higher volatility means that we obtain a higher excepted return based on the signal prediction. In sum, the strategy returns do not fluctuate with the market trend, becoming more significant by recognizing the underlying market sentiment.

Table 4. UpDown Signal Strategy Return and Systematic Risk

\begin{tabular}{|c|c|c|c|c|c|c|}
\hline \multirow{2}{*}{$\begin{array}{c}\mathrm{Y}= \\
\mathrm{X}= \\
\text { Std. Dev. of }\end{array}$} & \multicolumn{6}{|c|}{ Monthly Return of the Strategy based on UpDown Signal } \\
\hline & Daily M.R. & Overnight M.R. & Daytime M.R. & $M \cdot R_{30 \rightarrow e n d}$ & $M . R_{60 \rightarrow e n d}$ & $M . R \cdot 90 \rightarrow$ end \\
\hline \multirow[t]{2}{*}{ Intercept } & -0.009 & $0.023^{c}$ & -0.010 & -0.003 & -0.000 & 0.001 \\
\hline & $(-1.222)$ & $(4.704)$ & $(-1.252)$ & $(-0.378)$ & $(-0.028)$ & $(0.074)$ \\
\hline$X$ & $2.737 \mathrm{c}$ & $1.757^{b}$ & $2.975^{c}$ & $2.853^{c}$ & $2.815^{c}$ & $2.940^{c}$ \\
\hline
\end{tabular}


Table 4. Cont.

\begin{tabular}{|c|c|c|c|c|c|c|}
\hline \multirow[b]{2}{*}{$\begin{array}{c}X= \\
\text { Std. Dev. of }\end{array}$} & \multicolumn{6}{|c|}{ Monthly Return of the Strategy based on UpDown Signal } \\
\hline & Daily M.R. & Overnight M.R. & Daytime M.R. & $M \cdot R_{30 \rightarrow \text { end }}$ & $M . R_{60 \rightarrow \text { end }}$ & M. R. .90 $\rightarrow$ end \\
\hline & (6.130) & $(2.511)$ & $(5.870)$ & (5.018) & $(4.642)$ & $(4.681)$ \\
\hline$R^{2}$ & 0.169 & 0.033 & 0.157 & 0.120 & 0.104 & 0.106 \\
\hline
\end{tabular}

Note: Regression of several measures of market volatility on the monthly strategy returns is presented here. Monthly strategy return is the same as in Table 3. The variance of different daily market return within a month is used to calculate monthly volatility. The independent variables include daily return, overnight return, daytime return, and intraday return from 10:01 am, 10:31 am, and 11:01 am to the market close at 3:00 pm. The subscripts a, b, and c represent the $90 \%, 95 \%$, and $99 \%$ significance level, respectively.

\subsection{Strategy Return and Retail Investor Activity}

The above analysis implies that the intraday strategy returns are not due to the trading constraints and systemic risk factors. We now examine if the intraday pattern and strategy returns can be explained by retail investors' intraday sentiment. To tackle this issue, we need trading account data of individual investors, as in Kumar and Lee (2006), and the stocks on their watch lists; unfortunately, this data are not available. Without account data of individual investors, it is difficult to measure the overall activity of retail investors in the stock market. Instead, we look at the stocks that are popular among retail investors or are primarily traded by retail investors. We use firm characteristics to identify popular stocks for retail investors, and then construct portfolios to examine the performance of the intraday strategy related to investor activities.

We apply the same strategy to individual stocks instead of the index. The trading signal UDS of the stock is still based on the market-wide up/down movements. We choose $m$ from 10:01 am to 11:00 am without loss of generality. The strategy return of individual stock is defined by

$$
\text { avDailyReturn }_{a, t}=\sum_{m=10: 01}^{11: 00} \text { DailyReturn }_{a, t, m} / 60,
$$

where avDailyReturn $_{a, t}$ is the strategy return of stock $a$ in day $t$ and

$$
\text { DailyReturn }_{a, t, m}=\left\{\begin{aligned}
\text { InterdayReturn }_{a, t, m}, & \text { Updown Signal }_{m, t}>0, \\
- \text { InterdayReturn }_{a, t, m}, & \text { Updown Signal } \\
\text { In,t } & <0 .
\end{aligned}\right.
$$

The portfolio return then follows

$$
\text { PortfolioReturn }_{t}^{N}=\sum_{a \in N} w_{a, t} \text { avDailyReturn }{ }_{a, t},
$$

where $w_{a, t}=$ Size $_{a} / \sum_{n \in N}$ Size $_{n}$ is the value weighted portfolio weight of stock $a$ in the portfolio. An equal-weight portfolio is also examined and the results are the same.

First, simultaneous trading data are used in the portfolio construction. As an emerging market, most retail investors in the Chinese markets trade stocks directly. In the "Quality report of Chinese Stock Market 2015" from the SHSE, institutional investors can account for only $14 \%$ of the trading volume. This indicates that the 
trading volume is driven primarily by retail investors. Therefore, we introduce the daily trading value as a measure of the activity of retail investors.

Another measure is the value per transaction (VPT),

$$
V P T_{a, t}=\text { Total } \text { value }_{t}^{a} / \text { Trans. }_{t}^{a}
$$

where $\operatorname{Trans}_{t}{ }_{t}^{a}$ represent the numbers of transactions of stock $a$ during the time $t$. This measure for activity of retail investors introduced in Shapira \& Venezia (2001) is intuitive. With relative small capital and high transactions from retail investors, a low VPT means that retail investors are more active in trading a stock.

Since the market capitalization of an individual stock affects its value, we also use the Turnover Rate as a substitute variable. Simultaneous proxy means we use the trading data in day $t$ to form the portfolio on day $t$. Such portfolios are untradeable because we cannot realize its trading state before the strategy is executed. However, these portfolios can be used to check the relationship between strategy return and simultaneous activity of retail investors. All stocks are sorted into five different portfolios based on its daily Value, VPT, or Turnover Rate.

The portfolios are named S, 2, M, 4, and B, from small to big. The strategy returns of each portfolio are calculated based on (10). The daily return (in basis points) and the t-statistic for each portfolio are reported. In the last column, we also report the portfolio returns of longing portfolio $B$ and shorting portfolio $S$ simultaneously. The results of trading data proxy are reported in panel A of Table 5.

Second, we use several firm characteristics to group stocks to indicate their popularity among retail investors. Kumar and Lee (2006) examine the account data of retail investors and find that the retail investors prefer firms with small market capitalizations, high book/market ratio, fewer institutional shareholders, and lower market price. Based on their results, we consider the Size, B/M ratio, Shareholding Ratio of 10 Primary Shareholders, and stock price as proxies for the popular stocks of retail investors. Due to the data limitation in the Chinese markets, we use Shareholding Ratio of 10 Primary Shareholders for the institutional shareholders. Size and close price are computed by the closing price of the last month; B/M ratio and shareholding ratio of 10 primary shareholders are obtained from the statements of the previous quarter from "Wind" data. The results on the proxy portfolios, following Kumar and Lee (2006), are reported in panel B.

Finally, we consider particular data of the Chinese stock markets on the number of shareholders that are updated quarterly to meet the requirement of the SHSE and SZSE. Due to the limited numbers of institutional investors, the variation of the shareholders is primarily from the variation in retail investors. This implies that a large number of shareholders suggest that there are more retail investors. We study whether the strategy of investing in firms with more shareholders has a better return. On average, a large firm may have more shareholders than a small firm; however, this does not mean that the retail investors play a more important role in large firms. We use the size/holder ratio to measure the relative numbers of retail investors in each firm. A smaller size/holder ratio indicates a large impact of retail investors. The number of shareholders and size/holder ratio are obtained from the previous quarter's statement, and the results are reported in Panel C. 
Table 5. UpDown Signal Strategy Return and Retail Investors Activity

Panel A: Daily Excess Return (BPs)

Proxy = Amounts

\begin{tabular}{|c|c|c|c|c|c|}
\hline $\mathrm{S}$ & 2 & $\mathbf{M}$ & 4 & B & B-S \\
\hline 9.21 & 19.25 & 18.95 & 17.68 & 14.18 & 4.97 \\
\hline$(9.97)$ & $(10.35)$ & $(10.05)$ & $(9.41)$ & $(7.97)$ & $(3.94)$ \\
\hline \multicolumn{6}{|c|}{ Proxy $=$ Amounts Per Transaction } \\
\hline S & 2 & $\mathbf{M}$ & 4 & B & B-S \\
\hline 20.79 & 21.01 & 20.40 & 18.15 & 15.41 & -5.38 \\
\hline$(7.02)$ & $(7.17)$ & $(7.42)$ & $(6.83)$ & $(5.82)$ & $(-3.31)$ \\
\hline \multicolumn{6}{|c|}{ Proxy $=$ Turnover Rate } \\
\hline S & 2 & $\mathbf{M}$ & 4 & B & B-S \\
\hline 12.76 & 18.00 & 19.59 & 21.40 & 19.97 & 7.20 \\
\hline$(8.04)$ & $(9.52)$ & $(9.40)$ & $(9.58)$ & $(8.38)$ & $(5.06)$ \\
\hline
\end{tabular}

Panel B: Monthly Excess Return (\%)

\begin{tabular}{|c|c|c|c|c|c|}
\hline \multicolumn{6}{|c|}{ Proxy $=$ Last Month Size } \\
\hline S & 2 & $\mathbf{M}$ & 4 & B & B-S \\
\hline 3.64 & 4.13 & 3.96 & 3.73 & 2.76 & -0.87 \\
\hline$(10.22)$ & $(9.79)$ & $(9.61)$ & $(9.31)$ & $(7.94)$ & $(-4.48)$ \\
\hline \multicolumn{6}{|c|}{ Proxy = Last Quarter Book to Market ratio } \\
\hline S & 2 & $\mathbf{M}$ & 4 & B & B-S \\
\hline 2.70 & 3.07 & 3.25 & 3.32 & 3.49 & 0.78 \\
\hline$(7.57)$ & $(8.27)$ & $(8.42)$ & $(9.23)$ & $(9.29)$ & $(3.55)$ \\
\hline \multicolumn{6}{|c|}{ Proxy = Last Quarter Shareholding Ratio of 10 Primary Shareholders } \\
\hline S & 2 & $\mathbf{M}$ & 4 & B & B-S \\
\hline 3.68 & 3.52 & 3.77 & 3.47 & 2.83 & -0.85 \\
\hline$(9.08)$ & $(8.68)$ & $(9.37)$ & $(8.62)$ & $(7.55)$ & $(-4.44)$ \\
\hline \multicolumn{6}{|c|}{ Proxy $=$ Last Month Close Price } \\
\hline S & 2 & $\mathbf{M}$ & 4 & B & B-S \\
\hline 2.93 & 3.56 & 3.30 & 3.58 & 2.96 & 0.02 \\
\hline (8.46) & $(9.32)$ & $(8.58)$ & (9.16) & $(8.13)$ & (0.12) \\
\hline
\end{tabular}


Table 5. Cont.

\begin{tabular}{|c|c|c|c|c|c|}
\hline \multicolumn{6}{|c|}{ Panel C: Monthly Excess Return (\%) } \\
\hline \multicolumn{6}{|c|}{ Proxy = Last Quarter Number of Shareholders } \\
\hline$S$ & 2 & $\mathbf{M}$ & 4 & B & B-S \\
\hline 2.38 & 3.18 & 3.43 & 3.62 & 2.97 & 0.58 \\
\hline$(7.33)$ & $(8.96)$ & $(9.05)$ & $(9.05)$ & $(8.32)$ & (3.17) \\
\hline \multicolumn{6}{|c|}{ Proxy = Last Quarter Size per holders } \\
\hline S & 2 & $\mathbf{M}$ & 4 & B & B-S \\
\hline 4.11 & 4.21 & 4.06 & 3.60 & 2.51 & -1.59 \\
\hline$(9.64)$ & $(9.79)$ & $(9.80)$ & $(9.26)$ & $(7.38)$ & $(-7.08)$ \\
\hline
\end{tabular}

Note: We form the portfolio based on quintile break-points of measures related to activity of individual investors. First, we choose the simultaneous trading data, trading value, and VPT. The average daily returns (BPs) and their t-statistics (in parentheses) of these portfolios are in panel A. Second, some proxies from Kumar and Lee (2006) are chosen as measures of the preference of individual investors. These measures are Size (small size is preferred by individual investors), B/M Ratio (high value), Shareholding Ratio of 10 Primary Shareholders (small shareholding by institutional investors), and Price (low price). The average monthly returns (\%) and their t-statistics (in parentheses) of these portfolios are in panel B. Finally, we use the number of shareholders and market capitalization per shareholder to measure the activities of individual investors. Their monthly return (\%) and t-statistic (in parentheses) are reported in panel C. All portfolio returns are value-weight returns. In each panel, the results of Small to Big portfolios are from left to right. The sixth column "B-S" reports the return difference between portfolios B and S.

Except for the last month closing price portfolio, most of the results support the hypothesis that high retail investor activity explains high intraday strategy returns. In the untradeable case, the return of portfolio $S$ of unadjusted trading value is significantly smaller than that of other portfolios. However, for portfolios 2 to $B$, the strategy returns decrease with the trading amount, which is because of the less popular stocks with a large number of retail investors. In the alternative case of turnover rate, the phenomenon vanishes and the portfolio $\mathrm{B}-\mathrm{S}$ return is higher than the one in the value case. The VPT proxy performs very well. From portfolios $\mathrm{S}$ to $\mathrm{B}$, the strategy return reduces step-by-step, while the long-short portfolio, B-S, generates a return of 5.38 BPs per day. This provides evidence that the stocks with higher activity of retail investors are accompanied by higher sentiment strategy returns.

The popular stocks among the retail investors, as proposed by the measure in Kumar and Lee (2006), also gain a higher strategy return except the low price stocks. The portfolio monthly return differences between large size to small size $(-0.87 \%)$, high value to low value $(0.78 \%)$, and high institution holding to low institution holding $(-0.85 \%)$ are significantly different from zero. The discrepancy in the price may be caused by the differences in the market between the Chinese and the U.S. stock markets. For most points in time, the price gap is CNY 2-100 in the Chinese markets, which is far below the one in the U.S. markets. Therefore, the price difference for retail investors is very limited in the Chinese markets, which leads to insignificant differences among the price portfolios. 
Finally, the results of the shareholder-based portfolio are also consistent with the above results. As the number of shareholder increases, the strategy return increases from $2.38 \%$ to $2.97 \%$ per month. The decreasing return from portfolios 4 to $\mathrm{B}$ may be caused by the size effect too. With the adjusted proxy, size/holder ratio, a linear return reduction is observed with the increase in the activity of retail investors, together with the largest difference (1.59\% per month).

The cross-sectional analysis provides further evidence suggesting that the intraday strategy returns are driven by the short-term sentimental behaviors of retail investors. In our portfolio analysis, the stocks with high participation of or stocks that are preferred by retail investors achieve significantly high strategy returns, with the highest one of $4.21 \%$ monthly return on average during the sample period. This implies that the intraday sentiment pattern found in this study is economically and statistically significant. The behavior of retail investors is most likely driven by their short-term sentiment, which is directly affected by the prior intraday market-wide up/down fluctuations. ${ }^{2}$

\section{Intraday Return in the U.S. Stock Market}

Using the intraday data in the Chinese stock markets over 16 years, we have demonstrated that the intraday market-wide up (down) movements lead to positive (negative) subsequent intraday returns, and the corresponding strategy returns based on this intraday return pattern are not due to trading constraints and risk factors, but the activity of retail investors. In particular, the strategy returns are significantly high when the retail investors are more active in the market. We interpret this connection between early intraday marketwide movements to the subsequent intraday returns as intraday investor sentiment. Given that the Chinese stock markets are emerging markets that are dominated by retail investors, we expect that such intraday investor sentiment will not be observed in a mature market with more rational investors and less market friction. To examine this issue, we use the U.S. stock market data from January 2013 to December 2015 and investigate the predictive ability of the intraday market-wide up/down movements to the subsequent intraday returns in the U.S. markets.

We use several standard data sets from the Center for Research in Security Prices (CRSP). We consider the stocks with share codes of 10 or 11 in the CRSP that are listed in the NYSE, the AMEX, or the NASDAQ from January 2013 to December 2015. We collect the tickers of all these stocks from CRSP and label them ".N" for NYSE stocks, ".A" for AMEX stocks, and ".OQ" for NASDAQ stocks based on Reuters Instrument Codes (RIC) for the Thomson Reuters Tick History (TRTH) database. We collect intraday data for 15 minutes of all the stocks, including closing price, and trading volume, from TRTH intraday data. Daily data and market capitalization data are obtained from the CRSP, and quarterly book value of common equity data are from COMPUSTAT. The NYSE size break-points and the bookto-market break-points for each month are from Ken French's data library.

There are 4,607 listed firms in our sample including 1,554 NYSE stocks, 280 AMEX stocks, and 2,773 NASDAQ stocks. Due to the longer trading hours and larger number of stocks in the U.S. markets, we choose

2 This study only focuses on the intraday return and provides the intraday sentiment as a possible explanation. The long-term prediction (at daily or monthly lever) of the intraday signals introduced in this study and potentially different explanation are beyond the scope of this study due to more complicated anomalies (such as daily or monthly momentum) and higher information component in longer time span. We leave them to the future research. 
the 15-minute intervals to avoid the problem of the size and processing speed. We use the same method to study the predictive ability of the intraday sentiment signal, UDS. The value-weighted returns of all the stocks are considered since the equal-weighted returns deliver the same results. For the stocks listed in the NASDAQ, we only consider the main trading hours and ignore the pre- and after-market trading hours to match the NYSE and AMEX trading times.

We first run the regressions based on (3) for the UDS. We consider each possible $m$ as a 15-minute interval, and the regression results are reported in Panel A of Fig. 5. The blue bars and orange line represent the $\mathrm{R}^{2}$ and t-statistic for each regression. We also examine the intraday signal strategy on the U.S. stock markets as in (5). This means that we buy (sell) the market portfolio and hold to the market closing if the UDS is positive (negative) at time $m$. The strategy returns (blue bars in BPs) and their t-statistic (orange line) for each $m$ are reported in Panel B.

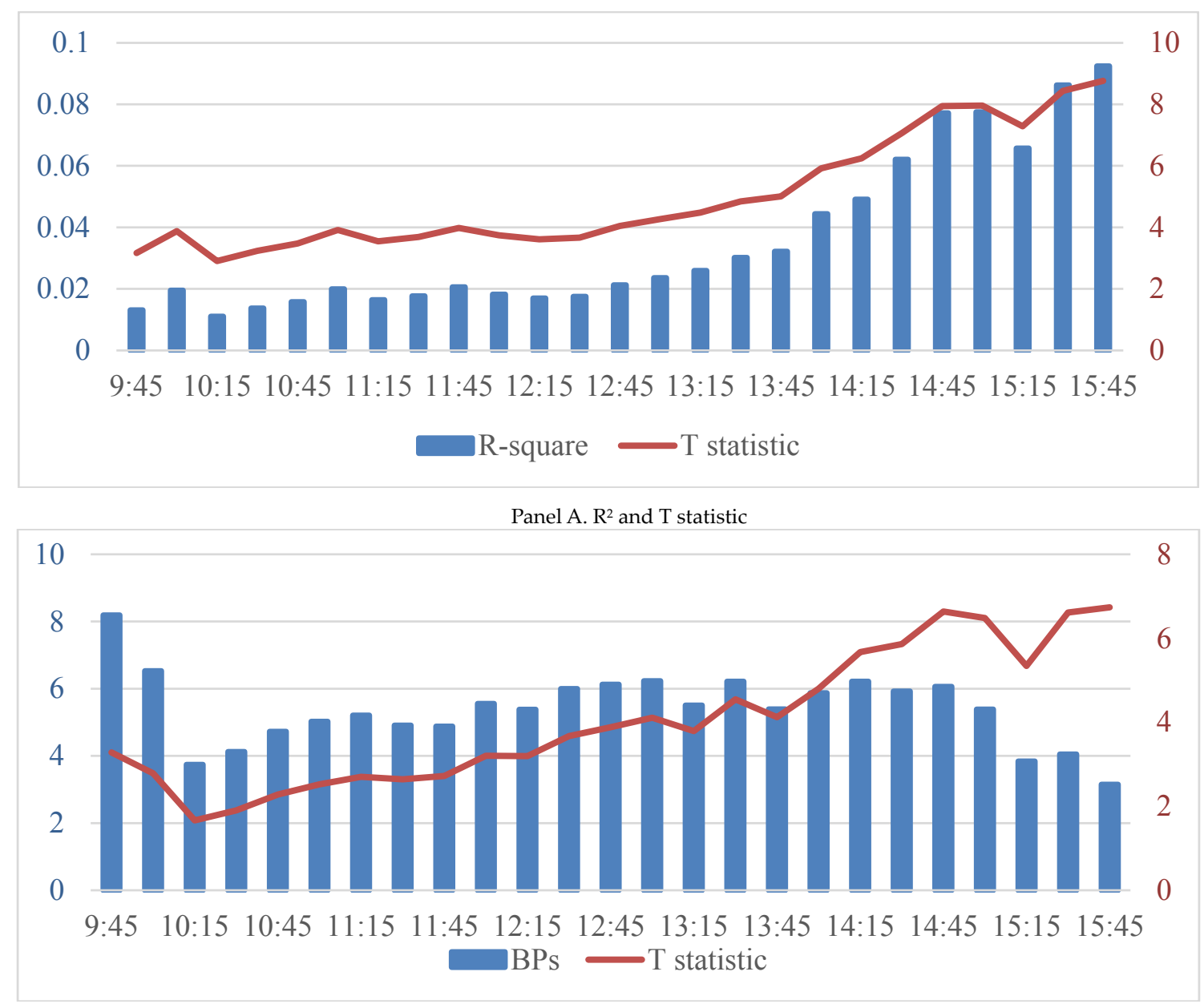

Panel B. Bias points and T statistic

Fig. 5 The Return Predictive ability and Daily Strategy Return of UpDown Signal in U.S. Stock Market Note: With the THTR intraday data of the U.S. data, we calculate UDS of the U.S. stock market in 15-minute intervals and report its predictive ability on the subsequent intraday value-weight market return. The stocks with share code 10 or 11 in CRSP and listed in NYSE, AMEX, or NASDAQ from Jan. 2013 to Dec. 2015 are included in our sample firms. We collect the tickers of all these stocks from CRSP and add the postfix ".N" for NYSE stocks, ".A" for AMEX stocks, 
and ".OQ" for NASDAQ stocks as its RIC for the TRTH database. The 15-minute intraday data of all stock include the close prices and trading volumes are obtained from the TRTH intraday database. We ignore the pre- and aftermarket trading time of NASDAQ to match the trading time of the NYSE. Panel A reports the result of regression of UDS on the subsequent intraday market return for every $m . R^{2}$ is reported on the primary y-axis (left) and t-statistics are reported on the secondary y-axis (right). Panel B reports the return (in BPs) of the UDS strategy and the t-statistic in every 15 minutes. BPs are reported on primary $y$-axis (left) and t-statistics are reported on the secondary $y$-axis (right).

Most of the results obtained in the U.S. markets are consistent with those in the Chinese markets. Panel A of Fig. 5 shows that, for all the intraday minutes, the correlation between the UDS and the subsequent intraday return is significantly positive in the U.S. markets. The t-statistics for each $m$ is greater than 3 (except the 10:15 am with a t-statistic of 2.90). The main difference from the Chinese markets is that the predictive ability of the UDS in the morning sessions becomes less significant in the afternoon. One possible explanation is that a large part of the intraday sentiment in the morning sessions is adjusted in the rest of the trading day. However, the significant coefficient of the UDS demonstrates that, even in a mature market, the intraday investor sentiment still exists, though it is more significant in the Chinese markets.

The sentiment strategy return is shown in Panel B. As compared to the daily return of 10-15 BPs in the Chinese markets, the strategy return in the U.S. markets is relatively small. Except for the first 30 minutes after market opening, the strategy returns for most $m$ values are between 4 to 6 BPs in the rest of the trading day. The highest strategy return of $8.19 \mathrm{BPs}$ is at 9:45 am. However, the strategy returns are significantly positive at most times. Except at 10:15 am and 10:30 am, all the t-statistics of the strategy returns are greater than 2, corresponding to the $95 \%$ significance level. The strategy returns become more significant as $m$ increases due to the shorter predicted time period.

In contrast to the Chinese markets, the regression and strategy analysis shows that the impact of the intraday investor sentiment reduces significantly in the U.S. markets due to the relative low participation of retail investors and less market friction. However, the significance of the impact from the intraday investor sentiment still exists even in a mature market.

With a relatively more efficient market than the Chinese markets, we now focus on the relationship between the strategy return and the activity of retail investors in the U.S. markets. We follow Kumar and Lee (2006) to construct portfolios with different retail investors' proxies, including market capitalization, B/M ratio, and price. Kumar and Lee (2006) argue that the retail investors prefer to hold the stock with small market capitalization, high B/M ratio, and low price. The monthly Market capitalization and B/M ratio portfolios are constructed based on the NYSE break points obtained from Ken French's data library. We explore whether the strategy return is due to the retail investor sentiment or the stocks with greater retail investor participation. We do not consider the Value and VPT as in Table 5 since data on the number of transactions of the NASDAQ stocks are not available. We also do not consider the shareholders due to lack of availability of data. 
Table 6. Strategy Return and Retail Investors Activity in U.S. Market

\begin{tabular}{|c|c|c|c|c|c|}
\hline \multicolumn{6}{|c|}{ Monthly Excess Return (\%) } \\
\hline \multicolumn{6}{|c|}{ Proxy = Last Month Size } \\
\hline $\mathrm{S}$ & 2 & $\mathbf{M}$ & 4 & B & B-S \\
\hline 2.80 & 2.11 & 1.66 & 1.35 & 1.10 & -1.70 \\
\hline$(4.59)$ & $(3.49)$ & $(3.08)$ & $(2.78)$ & $(2.54)$ & $(-4.07)$ \\
\hline \multicolumn{6}{|c|}{ Proxy = Last Quarter Book to Market ratio } \\
\hline$S$ & 2 & $\mathbf{M}$ & 4 & B & B-S \\
\hline 1.29 & 1.07 & 1.16 & 1.25 & 1.57 & 0.28 \\
\hline$(2.75)$ & $(2.46)$ & $(2.62)$ & $(2.76)$ & $(2.85)$ & $(0.81)$ \\
\hline \multicolumn{6}{|c|}{ Proxy = Last Month Close Price } \\
\hline $\mathrm{S}$ & 2 & $\mathbf{M}$ & 4 & B & B-S \\
\hline 2.18 & 1.88 & 1.70 & 1.27 & 1.13 & -1.05 \\
\hline$(3.02)$ & $(3.08)$ & $(3.30)$ & $(2.88)$ & $(2.57)$ & $(-2.10)$ \\
\hline
\end{tabular}

Note: Portfolios are based on measures related to the activity of individual investors. The results are based on the U.S. stock market data over 3 years. Some proxies from Kumar and Lee (2006) are used to measure the preference of individual investors, including Size (small size is preferred by individual investors), B/M Ratio (high value), and Price (low price). The average monthly returns (\%) and their t-statistics (in parentheses) of these portfolios are shown in panel B. Size and B/M Ratio portfolios are formed by NYSE breakpoint obtained from Ken French's data library. Price portfolios are formed by all stocks breakpoints.

Value-weight stock returns are introduced as portfolio returns and their t-statistics are reported.

The value-weighted portfolio returns and their t-statistics are reported in Table 6. Similar to the Chinese markets, all the results provide evidence regarding the intraday investor sentiment in the U.S. markets. The intraday sentiment strategy performs better with the stocks of small size, high value, and low price. In the B/M portfolios, the difference in return between portfolios $B$ and $S$ is not significant. However, the strategy returns increase from portfolios 2 to $\mathrm{B}$. The abnormal strategy return in portfolio $\mathrm{S}$ of $\mathrm{B} / \mathrm{M}$ may be caused by the stocks whose $\mathrm{B} / \mathrm{M}$ ratios are extremely low or even negative. These stocks are regarded as lottery-like stocks that have small probabilities to generate extremely high returns. The lottery-like stocks among retail investors and their behavior pattern have been studied in the literature (Kumar (2009) and An et al. (2015)). The phenomenon that emerges in the price portfolio is different from the one in the Chinese stock markets. In the U.S. markets, the price difference cannot be ignored by investors; therefore, we observe a significant difference in the strategy returns between the portfolios with small and large prices.

To sum up, the intraday sentiment signals predict the subsequent intraday market returns not only in an emerging market like China, but also in the markets like the U.S. Although the strategy returns are reduced remarkably in the U.S. markets, their significance and dependency on the retail investor activity indicate a similar intraday investor sentiment. The results imply that, as long as retail investors participate in the market, the prior intraday market-wide fluctuations affect the subsequent intraday market returns in the same direction. Therefore, the intraday investor sentiment plays an important role in explaining the subsequent intraday returns. 


\section{Conclusions}

There is a growing literature that suggests the important role played by sentiments in asset pricing (De et al. (1990); Barberis et al. (1998); Baker \& Wurgler (2006); Barberis et al. (2015)). In this study, we examine whether individual investors are influenced by the intraday market-wide up/down fluctuations and whether such intraday investor sentiment moves the subsequent intraday market in the same direction. We study the predictive ability of two different sentiment signals on the subsequent intraday return with Chinese data over 16 years and U.S. data over 3 years; one is the intraday market return and the other is Up-Down Signal, which measures the market-wide ups and downs of stocks. We find that both of indicators predict the subsequent intraday market returns, and the intraday strategy returns based on them are highly significant. In particular the morning Up-Down Signals are economically and significantly significant.

Several possible explanations, including trading limitations, systemic risk, and the activity of retail investors are examined. We demonstrate that trading limitations, such as " $\mathrm{T}+1$ " and short-sale constraints lead to high strategy returns on the long side of strategy. We also show that the sentiment strategy does not take any positive systemic risk and its profit is a result of market fluctuations that are greater when market volatility is high. Finally, motivated by the belief that naïve individual investors are more likely to be influenced by such simple intraday market-wide up/down movements, we conduct both time-series and cross-sectional analyses to examine the relationship between the intraday strategy returns and the activity of individual investors. The results support the hypothesis regarding intraday investor sentiment. More precisely, the time series analysis demonstrates that a high trading value and a lower value per transaction leads to high sentiment strategy returns. The cross-section analysis shows that high strategy returns are driven by the popular stocks among retail investors.

We also investigate the intraday return pattern in the U.S. stock markets. Even with fewer trading limitations that make arbitrage easier and a larger number of rational investors, the existence of individual investors still leads to a significant intraday sentiment pattern. The results of the cross-section analysis of retail investor activity are consistent with the Chinese markets. This implies that the intraday sentiment signals predict the subsequent intraday returns not only in emerging markets, but in mature markets as well.

Acknowledgements: We are particularly grateful to Xue-Zhong He, Jianfeng Yu, Jianxin Wang, Qiaoqiao Zhu, Xiaoguang Yang, Dehua Shen and Xiong Xiong for their helpful suggestions. We also thank the seminar participants at University of Technology, Sydney (UTS), Tianjin University (TU) and the 2015 Financial risk management under 'Big data' environment conference, Beijing. The first version of this paper was written while Shen Lin visited the Financial Discipline Group of Business School of UTS in 2016. Financial support from the National Natural Science Foundation of China (71201112, 71320107003 and 71532009) is gratefully acknowledged.

Conflicts of Interest: The authors declare no conflict of interest.

\section{References}

An, L., Wang, H., Wang, J., Yu, J., 2015. Lottery-related anomalies: The role of reference-dependent preferences. Social Science Research Network, doi:10.2139/ssrn.2636610. Available at: http://ssrn.com/abstract=2636610.

Antoniou, C., Doukas, J.A., Subrahmanyam, A., 2013. Cognitive dissonance, sentiment, and momentum. Journal of Financial and Quantitative Analysis 48, 245-275. 
Antweiler, W., Frank, M.Z., 2004. Is all that talk just noise? The information content of internet stock message boards. The Journal of Finance 59, 1259-1294.

Baker, M., Wurgler, J., 2006. Investor sentiment and the cross-section of stock returns. The Journal of Finance 61, 1645-1680.

Barberis, N., Greenwood, R., Jin, L., Shleifer, A., 2015. X-CAPM: An extrapolative capital asset pricing model. Journal of Financial Economics 115, 1-24.

Barberis, N., Shleifer, A., Vishny, R., 1998. A model of investor sentiment. Journal of Financial Economics 49, 307-343.

Bollen, J., Mao, H., Zeng, X., 2011. Twitter mood predicts the stock market. Journal of Computational Science 2, 1-8.

Chen, N.F., Kan, R., Miller, M.H., 1993. Are the Discounts on Closed-End Funds a Sentiment Index? The Journal of Finance 48, 795-800.

Chopra, N., Lee, C., Shleifer, A., Thaler, R.H., 1993. Yes, Discounts on Closed-End Funds Are a Sentiment Index. The Journal of Finance 48, 801-808.

Das, S.R., Chen, M.Y., 2007. Yahoo! for Amazon: Sentiment extraction from small talk on the web. Management Science 53, $1375-1388$.

De Long, J.B., Shleifer, A., Summers, L. H., Waldmann, R. J., 1990. Noise trader risk in financial markets. Journal of Political Economy 98 , $703-738$.

Fama, E.F., French, K.R., 1993. Common risk factors in the returns on stocks and bonds. Journal of Financial Economics 33, 3-56.

Fama, E.F., French, K.R., 1996. Multifactor explanations of asset pricing anomalies. The Journal of Finance 51, 55-84.

Fama, E.F., French, K.R., 1992. The cross-section of expected stock returns. The Journal of Finance 47, 427-465.

Gao, L., Han, Y., Li, S.Z., Zhou, G., 2015. Intraday Momentum: The First Half-Hour Return Predicts the Last Half-Hour Return. Social Science Research Network, doi:10.2139/ssrn.2440866. Available at: http://ssrn.com/abstract=2440866.

Harris, L., 1986. A transaction data study of weekly and intradaily patterns in stock returns, Journal of Financial Economics 16, 99-117.

Heston, S.L., Korajczyk, R.A., Sadka, R., 2010. Intraday Patterns in the Cross-section of Stock Returns. The Journal of Finance 65, 13691407.

Huang, D., Jiang, Y., Tu, J., Zhou, G., 2015. Investor sentiment aligned: A powerful predictor of stock returns. Review of Financial Studies 28, 791-837.

Jain, P.C., Joh, G., 1988. The dependence between hourly prices and trading volume, Journal of Financial and Quantitative Analysis 23, 269-283.

Jegadeesh, N., Wu, D., 2003. Word power: A new approach for content analysis. Journal of Financial Economics 110, 712-729.

Kumar, A., Lee, C., 2006. Retail investor sentiment and return co-movements. The Journal of Finance 61, 2451-2486.

Kumar, A., 2009. Who gambles in the stock market? The Journal of Finance 64, 1889-1933.

Lee, C., Shleifer, A., Thaler, R.H., 1991. Investor sentiment and the closed-end fund puzzle. The Journal of Finance 46, 75-109.

Loughran, T., McDonald, B., Yun, H., 2009. A wolf in sheep's clothing: The use of ethics-related terms in 10-K reports. Journal of Business Ethics 89, 39-49.

Ritter, J.R., 1991. The long-run performance of initial public offerings. The Journal of Finance 46, 3-27.

Shapira, Z., Venezia, I., 2001. Patterns of behavior of professionally managed and independent investors. Journal of Banking and Finance 25, 1573-1587.

Shleifer, A., Summers, L.H., 1990. The noise trader approach to finance. The Journal of Economic Perspectives 4, 19-33.

Stambaugh, R.F., Yu, J., Yuan, Y., 2014. The long of it: Odds that investor sentiment spuriously predicts anomaly returns. Journal of Financial Economics 114, 613-619.

Stambaugh, R.F., Yu, J., Yuan, Y., 2012. The short of it: Investor sentiment and anomalies. Journal of Financial Economics 104, $288-302$.

Stigler, G.J., 1964. Public regulation of the securities markets. The Journal of Business 37, 117-142. 
Tetlock, P. C., Saar-Tsechansky, M., Macskassy, S., 2008. More than words: Quantifying language to measure firms' fundamentals. The Journal of Finance 63, 1437-1467.

Tetlock, P.C., 2011. All the news that's fit to reprint: Do investors react to stale information? Review of Financial Studies 24, 1481-1512.

Tetlock, P.C., 2007. Giving content to investor sentiment: The role of media in the stock market. The Journal of Finance 62, $1139-1168$.

Wood, R.A., McInish, T.H., Ord, J.K., 1985. An investigation of transactions data for NYSE stocks. The Journal of Finance 40, 723-739.

Yu, J., 2013. A sentiment-based explanation of the forward premium puzzle. Journal of Monetary Economics 60, 474-491.

Zhang, X., Fuehres, H., Gloor, P.A., 2012. Predicting Asset Value through Twitter Buzz, in: Advances in Collective Intelligence 2011. Springer Berlin Heidelberg, Germany, pp. 23-34.

(C) 2016 by the authors. Published by Science Press (CSPM Ltd.). 